\title{
The Effects of Fiscal Policy Shocks in Bangladesh: An Agnostic Identification Procedure
}

By

\author{
Ataur Rahaman \\ Roberto Leon-Gonzalez
}

August 2020
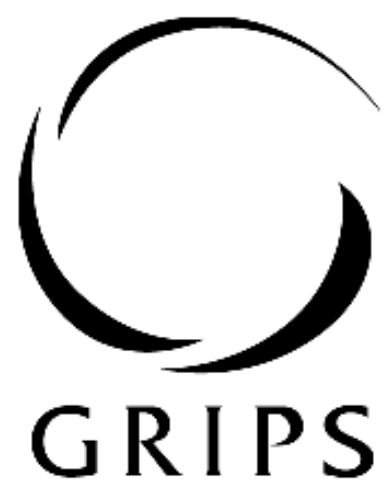

National Graduate institute FOR POLICY STUDIES

National Graduate Institute for Policy Studies

7-22-1 Roppongi, Minato-ku,

Tokyo, Japan 106-8677 


\title{
The Effects of Fiscal Policy Shocks in Bangladesh: An Agnostic Identification Procedure
}

August 2020

\author{
Ataur Rahaman ${ }^{1}$ \\ Roberto Leon-Gonzalez ${ }^{2}$
}

\begin{abstract}
This paper analyzes the macroeconomic effects of fiscal shocks in Bangladesh using the sign restriction approach in a Bayesian structural vector autoregression (SVAR) framework. We identify a generic business cycle shock to deal with the endogenous movement of fiscal variables along with a monetary policy shock to absorb the variations due to those shocks. Both unanticipated and anticipated fiscal shocks, that is, government expenditure and revenue shocks, are also identified by minimal sign restrictions. In identifying those shocks, we do not impose any restrictions on the sign of the key variable of interest. We find that private investment and consumption significantly increase due to expansionary government expenditure shock. Such an increase in private consumption is consistent with neo-Keynesian prediction. The fall in output due to the tax increase shock is highly robust. Private consumption also decreases due to a tax increase, although investment does not. The results suggest that fiscal policy, especially tax policy, is more effective than monetary policy in stabilizing output. Moreover, the fiscal authority could increase government expenditure without hurting private investment.
\end{abstract}

Keywords: Fiscal policy, Monetary policy, Business cycle, Bayesian VAR, Sign restrictions, Bangladesh, Fiscal shocks, Tax policy

JEL code C32, E62, H20, H30, H50

\footnotetext{
${ }^{1}$ Bangladesh Bank (Central Bank of Bangladesh), Dhaka, Bangladesh. email: a.rahaman@bb.org.bd (corresponding author)

${ }^{2}$ National Graduate Institute for Policy Studies (GRIPS), Tokyo, Japan. email: rlg@grips.ac.jp
}

The views, thoughts, and opinions expressed in the paper are those of the authors and do not necessarily represent those of the authors' employers or organizations. 


\section{Introduction}

Better macroeconomic management depends on an understanding of the impact of various policy shocks. Monetary and fiscal policy shocks are the most fundamental shocks. The lack of research on fiscal policy lies in the difficulty in identifying fiscal shocks. This occurs since fiscal shocks are i) rarely unanticipated, ii) endogenous, and iii) at times, accompanied by monetary policies. To identify structural shocks, some researchers have used recursive identification (e.g., Fatás and Mihov, 2001; Afonso and Sousa, 2012) or institutional details (e.g., Blanchard and Perotti, 2002; Perotti, 2004; Favero and Giavazzi, 2007) in a SVAR framework. Some employ the narrative/event study approach to isolate exogenous shocks; for example, Ramey and Shapiro (1998) and Ramey (2011) use this approach for exogenous spending shocks and Romer and Romer (2010) for tax shocks. However, their findings regarding an increase in government spending differ. The narrative approach finds that private consumption and real wages fall, which accords with neoclassical models, whereas the SVAR approach finds the opposite sign, which is consistent with neoKeynesian models. The latter use a comparatively new sign restriction approach, for example, as in Mountford and Uhlig (2009) and Canova and Pappa (2007). Most of their findings agree with the SVAR approach in Blanchard and Perotti (2002).

In the Bangladesh context, most studies find that monetary policy does not have any impact on the output of Bangladesh (e.g., Alam, 2015). However, there is no recent study on the effects of fiscal policy in Bangladesh. Thus, the ineffectiveness of monetary policy and the lack of fiscal policy studies raise the question: what are the macroeconomic effects of fiscal policy in Bangladesh?

Previously, to the best of our knowledge, Nahar and Siriwardana (2013) use a computable general equilibrium model (CGE) to study the impacts of tariff reform in Bangladesh. Ducanes, Cagas, Qin, Quising, and Razzaque (2006) use structural macroeconomic model simulations to study the effects of fiscal policies in several countries including Bangladesh. However, both studies deploy model simulations and are not entirely data driven. Our paper is the first to answer the aforementioned critical policy question using the sign restriction method developed by Arias, Rubio-Ramírez, and Waggoner (2018) in a Bayesian structural vector autoregression (BSVAR) framework.

We use the sign restriction approach in the BSVAR framework for two reasons. First, the narrative approach is not possible for Bangladesh as it does not have a history of any war after independence nor does it have detailed narrative records of tax policies necessary to identify narrative exogenous spending and tax shocks. Second, among other SVAR methods, the sign restriction approach imposes minimal restrictions on impulses to identify the shocks based on economic theories. Moreover, it does not impose any restriction on key variables but remains agnostic about their behavior.

Following Mountford and Uhlig (2009), we use a generic business cycle shock to deal with the endogenous movements of fiscal variables along with a monetary policy shock to absorb as much of the variations as possible due to those shocks. The unanticipated and anticipated fiscal shocks are also identified using minimal sign restrictions. However, the penalty function approach (PFA) of the sign restriction developed by Mountford and Uhlig (2009) has serious drawbacks as pointed out by Arias et al. (2018): i) PFA does not draw from correct posterior distribution, ii) it imposes additional sign or zero restrictions that bias the impulse response function, and violates agnosticism, and iii) it produces incorrect inference by creating artificially narrow confidence intervals. Thus, this paper uses the newly developed sign restriction method and algorithm of Arias et al. (2018), examining annual data from 1974 to 2017, following the Bayesian method due to our small sample size. 
We find that private investment, private consumption, and wages (although wage is not significant) increase due to expansionary government expenditure shock. The increase in private consumption and wages is consistent with neo-Keynesian predictions and other SVAR results, for example, in Blanchard and Perotti (2002) and Mountford and Uhlig (2009). A fall in output due to tax hike shocks is highly robust. Private consumption also decreases due to a tax increase, although investment does not. The business cycle and government revenue shocks contribute the most (around 28\% each) to the variation of output, while government expenditure does not contribute.

The remainder of this paper is organized as follows. Section 2 provides a brief review of the related literature. Section 3 describes our methodology and data. This is followed by Section 4, where we discuss the empirical results, and the final section contains our conclusion and policy implications.

\section{Literature Review}

There is considerable debate about the effects of fiscal policy in the literature. Neoclassical models (e.g., Baxter \& King, 1993) assume lump-sum taxes, government expenditure viewed as waste, perfect competition in factor and goods markets, a production function with a constant return to scale, and a separable utility function (between consumption and leisure). In such models, due to government inter-temporal budget constraints, any increase in government expenditure needs to be accommodated by an increase in the tax rate of the same amount. Thus, forward-looking agents react by reducing both consumption and leisure due to the drop in after-tax labor income. Therefore, both wages (due to an increase in the labor supply) and consumption fall, implying that the increase in GDP is less than the increase in government expenditure, or the multiplier is less than one.

In contrast, neo-Keynesian models give the opposite conclusion. An increase in government expenditure leads to a shift in labor demand that causes real wages to increase. As a result, consumption increases due to an increase in real wages, GDP also rises, and the output multiplier is typically larger than one (see, Perotti, 2007, for a summary of recent theoretical models).

While theoretical models have the disadvantage of relying on restrictive assumptions, the distinction between exogenous and endogenous shocks in these models is clear. However, empirical models are data driven and come with difficulties. Empirical research (e.g., Blanchard and Perotti, 2002; Perotti, 2004, 2007; Canova and Pappa, 2007; Ramey, 2011; Mountford and Uhlig, 2009) encounters the following difficulties. i) Fiscal shocks are usually anticipated due to a decision lag and implementation lag. By this time, economic agents have accommodated the shocks into their economic decisions long before the shock hits. ii) The fiscal shocks are endogenous; they move with the economic conditions or the business cycle, even though the fiscal policy is unchanged. iii) Fiscal policies are sometimes accompanied by monetary policy that makes further difficulties in isolating the effect of the fiscal shocks from the monetary policy. The empirical literature has several solutions to these difficulties, which we will review in detail.

The empirical literature that analyzes fiscal shocks using VAR can be classified into five broad categories. The first assumes a recursive ordering of the variables in terms of their contemporaneous effect on other variables so that the Cholesky decomposition can be used to identify structural shocks; examples are Fatás and Mihov (2001) and Afonso and Sousa (2012) using BSVAR. However, the ordering of the variables in terms of the contemporaneous effect is restrictive.

The second category is the method in Blanchard and Perotti (2002), the most dominant and famous in fiscal policy study. They use institutional details about transfer, 
spending, taxes, and the timing of tax collection in the US to identify exogenous shocks, and hold that fiscal policy variables do not react within four quarters due to other unanticipated shocks. They find that an increase in government expenditure (tax) has a positive (negative) effect on output, and a rise in both has a strong negative impact on private investment. Perotti (2004) expands on the efforts of Blanchard and Perotti (2002), including inflation and interest rates, while analyzing the effects of fiscal policy in five OECD countries.

The third category is the popular narrative/event-study approach, where narrative records, for example, presidential speeches, and war spending buildup, are used to define pure exogenous shocks. Ramey and Shapiro (1998) employ this method to analyze the impact of government spending for the first time in fiscal policy. They use the wartime spending buildup of the US as an exogenous spending shock. Ramey (2011) extends this methodology by incorporating the timing of the shocks from business news to measure anticipation of the shocks. However, the application of the narrative approach to tax shocks requires detailed records of a country's tax changes. To isolate the exogenous tax changes from endogenous ones, Romer and Romer (2010) use detailed narrative documents, such as presidential speeches and congressional reports, to identify the motives, timing, and size of tax changes in the US.

The findings of the SVAR and the narrative approach are different, especially in the case of consumption and real wages. The narrative method of Ramey and Shapiro (1998) and Ramey (2011) find that output increases, but private consumption and real wages fall due to the exogenous rise in wartime spending, which accord with the neoclassical models. However, the SVAR approach used by Fatás and Mihov (2001), Blanchard and Perotti (2002), and Perotti (2004) generally finds an opposite sign for consumption and real wages, consistent with neo-Keynesian models. In the case of tax shocks, the narrative approach finds a significantly more substantial and robust effect on output compared with the SVAR approach; the difference being due to the timing of the shocks (Romer \& Romer, 2010).

The fourth category for the method of identifying fiscal shocks is a relatively new sign restriction approach on impulse responses, which has fewer assumptions and imposes no restrictions on the primary variable of interest. The most dominant method is the PFA of Mountford and Uhlig (2009), where they identify the business cycle shock first, then the monetary policy shock by sign restriction based on economic theory to separate the automatic movement of fiscal variables and to absorb as much variation as possible due to those shocks. Afterward government expenditure and tax shocks are identified by minimal sign restrictions. The findings of the impact on GDP due to government expenditure and tax shocks are similar to those in Blanchard and Perotti (2002). However, Mountford and Uhlig (2009) find that the tax multiplier is larger than the spending multiplier, which is the opposite of the finding in Blanchard and Perotti (2002). Canova and Pappa (2007) use sign restriction on the crosscorrelation function to analyze price differentials due to fiscal shocks in the US and European Union countries. They find that a distortionary balance budget (expansionary fiscal) shock leads to negative (positive) price differentials.

Finally, in the fifth category, Dungey and Fry (2009) combine traditional short-run restrictions, long-run cointegrating relationships, and sign restrictions on impulse responses to identify fiscal and monetary policy shocks in New Zealand. Their study is the first to combine three mechanisms in a single VAR system. They find that tax and debt policy shocks have more impact than the government expenditure shock.

Most literature analyzes fiscal shocks in the US economy and other advanced economies, but study of these shocks in developing countries is rare. Surprisingly, to the best of our knowledge, no study has analyzed the impact of fiscal policy in the case of Bangladesh (there are some descriptive country reports of international and government organizations, but no empirical literature that uses econometric methods to analyze its fiscal shocks). 
Ducanes et al. (2006) use structural macroeconomic model simulations to examine the impact of targeted and untargeted government spending increases and a tax cut in Bangladesh, China, Indonesia, and the Philippines. They find that the short-run multiplier of untargeted government spending is much less than the capital spending targeted multiplier and increased fiscal spending is not stabilizing in Bangladesh and Indonesia. Nahar and Siriwardana (2013), based on a CGE model, argue that fiscal compensation with a consumption tax will increase poverty and inequality in Bangladesh. However, both studies employ model simulations, based on more restrictive assumptions and equations, and are not entirely data driven. They also do not provide a clear answer about the fiscal shocks.

To summarize, the study of fiscal policy has been generally limited to the US and developed countries, with almost no study in Bangladesh. Our study fills this gap. Among the alternative methods recently developed that try to solve the problems related to identifying fiscal shocks (i.e., endogeneity of fiscal shocks, lags in implementation or anticipation of shocks by agents, and separation of monetary policy), the sign restriction approach in the BSVAR framework includes fewer restrictions and needs fewer prior assumptions. Although the narrative approach identifies the exogenous shocks directly, institutional details, parliamentary speeches, and discussions are not available in the case of Bangladesh. In addition, there has been no war since its independence in 1971, which is needed to identify narrative spending shocks. Given this backdrop, we analyze the macroeconomic effects of the fiscal policy of Bangladesh by using sign restrictions on impulse response functions in a BSVAR framework.

\section{Methodology}

\subsection{The Model}

Consider the SVAR in general form:

$$
\boldsymbol{y}_{t}^{\prime} \boldsymbol{D}_{0}=\sum_{l=1}^{p} \boldsymbol{y}_{t-1}^{\prime} \boldsymbol{D}_{l}+\boldsymbol{c}+\boldsymbol{\eta}_{t}^{\prime} \text { for } 1 \leq t \leq T,
$$

where $\boldsymbol{y}_{t}$ is an $n \times 1$ vector of endogenous variables, $p$ is the lag length of the VAR, $\boldsymbol{D}_{l}$ is an $n \times n$ matrix of parameters, $\boldsymbol{c}$ is a $1 \times n$ vector of parameters, and $T$ is the sample size. The $n \times 1$ vector $\boldsymbol{\eta}_{t}$ is Gaussian with a mean zero and covariance matrix $\mathbf{I}_{n}(n \times n$ identity matrix), or

$$
\boldsymbol{\eta}_{t} \sim \mathcal{N}\left(0, \mathbf{I}_{n}\right)
$$

We can write the model described in equation (1) in a more compact form as

$$
\boldsymbol{y}_{t}^{\prime} \boldsymbol{D}_{0}=\boldsymbol{X}_{t}^{\prime} \boldsymbol{D}+\boldsymbol{\eta}_{t}^{\prime} \text { for } 1 \leq t \leq T,
$$

where, $\boldsymbol{D}^{\prime}=\left[\begin{array}{lll}\boldsymbol{D}_{1}^{\prime} & \ldots & \boldsymbol{D}_{p}^{\prime}\end{array} \boldsymbol{c}^{\prime}\right]$ and $\boldsymbol{X}_{t}^{\prime}=\left[\begin{array}{llll}\boldsymbol{y}_{t-1}^{\prime} & \ldots & \boldsymbol{y}_{t-p}^{\prime} & 1\end{array}\right]$. Thus, $\boldsymbol{D}$ is a $k \times n$ matrix, with $k=n p+1$. We can write the reduced-form representation of the SVAR given in equation (2) as follows:

$$
\boldsymbol{y}_{t}^{\prime}=\boldsymbol{X}_{t}^{\prime} \boldsymbol{B}+\boldsymbol{\varepsilon}_{t}^{\prime} \text { for } 1 \leq t \leq T,
$$

where, $\boldsymbol{B}=\boldsymbol{D} \boldsymbol{D}_{0}^{-1}, \boldsymbol{\varepsilon}_{t}^{\prime}=\boldsymbol{\eta}_{t}^{\prime} \boldsymbol{D}_{0}^{-1}$, and $\mathbb{E}\left[\boldsymbol{\varepsilon}_{t} \boldsymbol{\varepsilon}_{t}^{\prime}\right]=\boldsymbol{\Sigma}=\left(\boldsymbol{D}_{0} \boldsymbol{D}_{0}^{\prime}\right)^{-1}$. We estimate the reducedform parameters $\boldsymbol{B}$ and $\boldsymbol{\Sigma}$ in a BVAR framework because it works better for a small sample size, and use a sign-restriction approach to identify the structural parameters $\boldsymbol{D}_{0}$ and $\boldsymbol{D}$, which we discuss later.

To estimate the model in equation (3) in a BVAR framework, we need to define the prior distributions for $\boldsymbol{B}$ and $\boldsymbol{\Sigma}$. We use normal-Wishart distribution for priors for two reasons, i) normal-Wishart is a conjugate, meaning that the posterior distribution will be the same family as the prior distribution, and ii) the sign-restriction approach developed by Arias et al. (2018) works best for this prior. 
Given the prior distribution characterized as normal-inverse Wishart distribution $\operatorname{NIW}\left(\alpha_{0}, \boldsymbol{\omega}_{0}, \boldsymbol{\beta}_{0}, \boldsymbol{\Phi}_{0}\right)$, we can obtain the posterior distribution as $\operatorname{NIW}(\bar{\alpha}, \overline{\boldsymbol{\omega}}, \overline{\boldsymbol{\beta}}, \overline{\boldsymbol{\Phi}})$. Following Dieppe et al. (2016) and Arias et al. (2018), we can write this posterior distribution as

where,

$$
\begin{aligned}
\operatorname{NIW}_{(\bar{\alpha}, \overline{\boldsymbol{\omega}}, \overline{\boldsymbol{\beta}}, \overline{\boldsymbol{\Phi}})}(\boldsymbol{B}, \boldsymbol{\Sigma} \mid \mathbf{y}) & \propto|\boldsymbol{\Sigma}|^{-k / 2} \exp \left[-\frac{1}{2}(\boldsymbol{\beta}-\overline{\boldsymbol{\beta}})^{\prime}(\boldsymbol{\Sigma} \otimes \overline{\boldsymbol{\Phi}})^{-1}(\boldsymbol{\beta}-\overline{\boldsymbol{\beta}})\right] \\
& \times|\boldsymbol{\Sigma}|^{-(\bar{\alpha}+n+1) / 2} \exp \left[-\frac{1}{2} \operatorname{tr}\left\{\boldsymbol{\Sigma}^{-1} \overline{\boldsymbol{\omega}}\right\}\right]
\end{aligned}
$$

$$
\begin{aligned}
& \bar{\alpha}=T+\alpha_{0} \\
& \overline{\boldsymbol{\Phi}}=\left[\boldsymbol{\Phi}_{0}^{-1}+\boldsymbol{X}^{\prime} \boldsymbol{X}\right]^{-1} \\
& \overline{\boldsymbol{B}}=\overline{\boldsymbol{\Phi}}\left[\boldsymbol{\Phi}_{0}^{-1} \boldsymbol{B}_{0}+\boldsymbol{X}^{\prime} \boldsymbol{Y}\right\rceil \\
& \overline{\boldsymbol{\omega}}=\boldsymbol{Y}^{\prime} \boldsymbol{Y}+\boldsymbol{\omega}_{0}+\boldsymbol{B}_{0}^{\prime} \boldsymbol{\Phi}_{0}^{-1} \boldsymbol{B}_{0}-\overline{\boldsymbol{B}}^{\prime} \overline{\boldsymbol{\Phi}}^{-1} \overline{\boldsymbol{B}} \\
& \overline{\boldsymbol{\beta}}=\operatorname{vec}(\overline{\boldsymbol{B}}), \quad \boldsymbol{\beta}_{0}=\operatorname{vec}\left(\boldsymbol{B}_{0}\right) .
\end{aligned}
$$

However, our main concern is to convert $\boldsymbol{\varepsilon}_{t}^{\prime}$, the one-step-ahead forecast error, into economically meaningful or structural shocks $\boldsymbol{\eta}_{t}^{\prime}$. We assume that the structural shocks are orthogonal, or $\mathbb{E}\left[\boldsymbol{\eta}_{t} \boldsymbol{\eta}_{t}^{\prime}\right]=\mathbf{I}_{n}$. From equations (2) and (3), it is clear that the identification of all $n$ shocks means finding a structural matrix $\boldsymbol{D}_{0}^{-1}$, such that $\boldsymbol{\varepsilon}_{t}^{\prime}=\boldsymbol{\eta}_{t}^{\prime} \boldsymbol{D}_{0}^{-1}$, and $\mathbb{E}\left[\boldsymbol{\varepsilon}_{t} \boldsymbol{\varepsilon}_{t}^{\prime}\right]=$ $\boldsymbol{\Sigma}=\left(\boldsymbol{D}_{0} \boldsymbol{D}_{0}^{\prime}\right)^{-1}$. The identification of the structural matrix $\boldsymbol{D}_{0}^{-1}$ requires imposing $n(n-1) / 2$ restrictions on $\boldsymbol{D}_{0}^{-1}$. In the frequentist VAR literature, researchers employ several methods to identify the whole structural matrix $\boldsymbol{D}_{0}^{-1}$, such as i) using a Cholesky decomposition of $\boldsymbol{D}_{0}^{-1}$ by assuming a recursive ordering or contemporaneous and lag response of variables in the VAR (see Sims, 1986), ii) imposing $n(n-1) / 2$ restrictions either by assuming a short-run structural relationship (see Bernanke,1986), or iii) a long-run structural relationship (see Blanchard and Quah, 1989), or iv) both short- and long-run relationships among variables (see Gali, 1992).

Instead of identifying all $n$ fundamental shocks, we use the sign restriction approach to identify shocks related to our research question. However, several novel methodologies are available for this. We use the sign and zero restriction method developed by Arias et al. (2018) for several reasons: i) the pure sign restriction approach of Faust (1998) and Uhlig (2005) are applicable to identify only one structural shock, ii) the well-known PFA of Mountford and Uhlig (2009) has serious drawbacks as discussed in Arias et al. (2018), and iii) the method of Baumeister and Hamilton (2015) uses a Metropolis-Hastings algorithm to directly draw from the posterior parameter, which could be computationally inefficient in a large variable model, as we have here. The methodology and algorithm developed by Arias et al. (2018) are efficient and correctly draw from the posterior of the structural parameters. Their method permits us to implement sign and zero restrictions at any horizon of the impulse response function (IRF). Following Arias et al. (2014 and 2018), the matrix $\mathbf{L}_{h}\left(\boldsymbol{D}_{0}, \boldsymbol{D}\right)$ represents the IRF of the $i$ th variable to the $j$ th structural shock at horizon $h$, where $\mathbf{L}_{0}\left(\boldsymbol{D}_{0}, \boldsymbol{D}\right)=\left(\boldsymbol{D}_{0}^{-1}\right)^{\prime}$ and $\mathbf{L}_{h}\left(\boldsymbol{D}_{0}, \boldsymbol{D}\right)=\sum_{l}^{\min (h, p)}\left(\boldsymbol{D}_{l} \boldsymbol{D}_{0}^{-1}\right)^{\prime} \times \mathbf{L}_{h-l}\left(\boldsymbol{D}_{0}, \boldsymbol{D}\right)$, for $h>0$. The sign and zero restrictions on shock $j$ will hold if

$$
\boldsymbol{S}_{j} \times \boldsymbol{F}\left(\boldsymbol{D}_{0}, \boldsymbol{D}\right) e_{j}>0 \text {; and } \boldsymbol{Z}_{j} \times \boldsymbol{F}\left(\boldsymbol{D}_{0}, \boldsymbol{D}\right) e_{j}=0
$$

where $\boldsymbol{F}\left(\boldsymbol{D}_{0}, \boldsymbol{D}\right)$ is the $r \times n$ matrix such that the structural impulse responses of the desired horizons $(h)$ we impose restrictions on, $\mathbf{L}_{h}\left(\boldsymbol{D}_{0}, \boldsymbol{D}\right)$, are stacked; $\boldsymbol{S}_{j}$ and $\boldsymbol{Z}_{j}$ are the selection matrices of size $s_{j} \times r$ and $z_{j} \times r, 0 \leq s_{j}$ and $0 \leq z_{j} \leq n$ for $1 \leq j \leq n$; each row represents one restriction with all zeros except the entry represents the restriction with one (for positive sing restriction in $\boldsymbol{S}_{j}$ and zero restriction in $\boldsymbol{Z}_{j}$ ) or a minus one (for negative sign restriction). $e_{j}$ is the $j$ th column of the identity matrix of size $n$. For details, see Arias et al. (2018). 


\subsection{Identification of Fiscal Policy Shocks}

Economists define a policy shock as a sudden change in policy variables. While monetary policy shocks are well understood by a sudden increase in interest rates, it is less clear in the case of fiscal policy shocks. Fiscal variables, that is, government expenditure and tax revenue, take several forms, and the impacts are not necessarily the same. However, in this paper, we consider fiscal variables as broader or in the macro-economic sense as defined in the literature, such as in Blanchard and Perotti (2002), Mountford and Uhlig (2009), and Dungey and Fry (2009). In other words, we consider the impact of aggregate fiscal variables on aggregate macroeconomic variables.

Generally, we follow the fiscal policy identification strategy of Mountford and Uhlig (2009), where the strategy involves the identification of four shocks. First, we identify a generic business cycle shock defined as the positive sign restriction on GDP, private consumption, private investment, and government revenue for two years. This shock is defined so that the model can separate revenue shock — which is an increase in revenue only - with the increase in revenue due to a business cycle shock — which is an increase in revenue due to favorable economic conditions or an increase in GDP, consumption, and investment. Second, a monetary policy shock is defined as a shock that increases interest rate and reduces the consumer price index (CPI) for two years following the shock. Finally, we define two unanticipated fiscal shocks: government expenditure shock as a positive sign restriction on the response of government expenditure and GDP for two years (in contrast to Mountford and Uhlig, 2009). We restrict GDP because GDP identity implies that government expenditure has a direct impact on GDP. In identifying government expenditure shocks, Canova and Pappa (2007) also impose a positive correlation restriction between GDP and government expenditure. For the government revenue shock, we only impose positive sign restrictions on it (Dungey \& Fry, 2009; Mountford \& Uhlig, 2009). However, Mountford and Uhlig (2009) require monetary policy shocks to be orthogonal to business cycle shocks, and the two fiscal shocks are orthogonal to both the business cycle and monetary policy shocks, without being orthogonal between them. Instead, we follow the conventional methodology, where all four shocks are orthogonal to each other. A summary of these identifying restrictions is presented in Table 1.

Table 1

Identification Restrictions

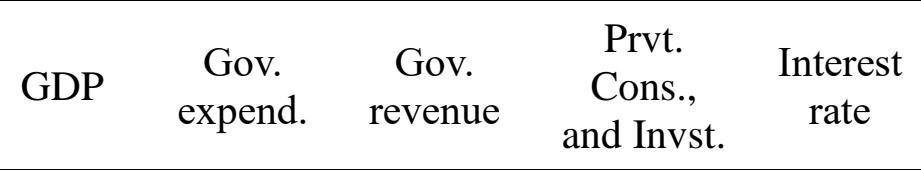

CPI

\section{Non-fiscal shocks}

Business cycle

Monetary policy

\section{Fiscal policy shocks}

Government expenditure

Government revenue

A '+' (-) implies that the impulse response of the variable in the cell is restricted to positive (negative) for two years following the shock, including the impact year. The blank entry represents no restriction. 
Mountford and Uhlig (2009) also define anticipated fiscal shocks as forward-looking economic agents anticipate such fiscal shocks before they hit the economy. For example, individuals and firms can predict the impact of an increase in taxes before it is actually implemented; hence, fiscal shocks happen earlier. Following Mountford and Uhlig (2009), anticipated fiscal shocks are defined as shocks where government expenditure (revenue) increases only in the second year but does not show any response (zero response) the first year following the shock. The one-year assumption for anticipation is reasonable, as the government of Bangladesh declares a yearly budget, and political debates and necessary legislation happen during the year. The restrictions for the business cycle and monetary policy shocks remain the same as in the unanticipated shocks model.

However, instead of the PFA developed by Mountford and Uhlig (2009), we use the methodology of Arias et al. (2018) to impose the restrictions and estimate the SVAR. The PFA has severe drawbacks as we have mentioned earlier. Arias et al. (2014) do not find the significance of fiscal shocks by employing their sign restriction method with the same dataset and identification strategy of Mountford and Uhlig (2009).

\subsection{Data and VAR Specification}

Our VAR model includes GDP, government expenditure, government revenue, the interest rate, the CPI, private consumption, and private investment. Following Blanchard and Perotti (2002), government revenue is only tax revenue. Whereas, government expenditure is total government expenditure minus transfers (as in Favero \& Giavazzi, 2007) because according to the classification of the Bangladesh Bureau of Statistics (BBS), transfer payments are part of total government expenditure. However, Blanchard and Perotti (2002) subtract transfers from revenue. This is our base specification, which we call 7VAR (7 variables); all our results are based on this 7VAR, unless stated otherwise. In addition, we estimate two more VAR models, 5VAR and 11VAR, with 5 and 11 variables, respectively, for robustness checks and comparisons (see Section 4.9).

Data are collected from various issues of the Statistical Year Book of Bangladesh, published by the BBS, except the interest rate, which is obtained from the International Financial Statistics (IFS) database. All the national account variables are converted to real per capita terms from their level divided by a GDP deflator and mid-year population. All variables are in log form, except the interest rate. Data are annual ranges from 1974 to 2017 because quarterly frequency is not available for Bangladesh. In addition, as argued by Perotti (2007) and Ramey (2011), annual frequency reduces the problem of anticipation.

The VAR has no constant and time trend, and, according to Uhlig (1994, 2005), this ensures more robust results. We select one lag, as in Canova and Pappa (2007) because of our small sample size. However, we check the results with a higher lag, and we select two lags in the smaller 5VAR case for comparison. We use an uninformative normal-Wishart prior following Uhlig $(1994,2005)$ and Arias et al. (2018). Specifically, we set

$$
\alpha_{0}=0, S_{0}=0, \beta_{0}=0, \Phi_{0}=0 .
$$

The results are based on 3,000 independent draws from the posteriors conditional on sign restrictions. We use a Matlab code written by Breitenlechner, Geiger, and Sindermann (2019), slightly modified for our estimation.

\section{Results}

The impulse responses of the macroeconomic variables for the identified business cycle, monetary policy, government expenditure, and government revenue shocks are shown in Figures 1-8. We plot the median responses or $50^{\text {th }}$ quantile in the solid line, and the $16^{\text {th }}$ and $84^{\text {th }}$ quantiles in shaded areas for the horizons 0 to 20 years after the shocks. The vertical shaded area represents the sign restrictions imposed to identify the shock. 


\subsection{Business Cycle Shock}

The impulse responses of the business cycle shock are shown in Figure 1. The vertical shaded areas in the responses of GDP, government revenue, private consumption, and private investment represent the identifying restrictions on the impulses, where we restrict these to be positive for two years after the shocks, including the year of impact. Given that we do not restrict the impulses after two years, the responses of GDP and private consumption do not return to zero, and government revenue and private investment decrease gradually after the shock, but remain positive, implying that the responses to the shock are persistent. Due to business cycle shock, price level rises, which is significant in the third year and onward, and also persistent. The increase in price level is consistent with the findings of Mountford and Uhlig (2009).
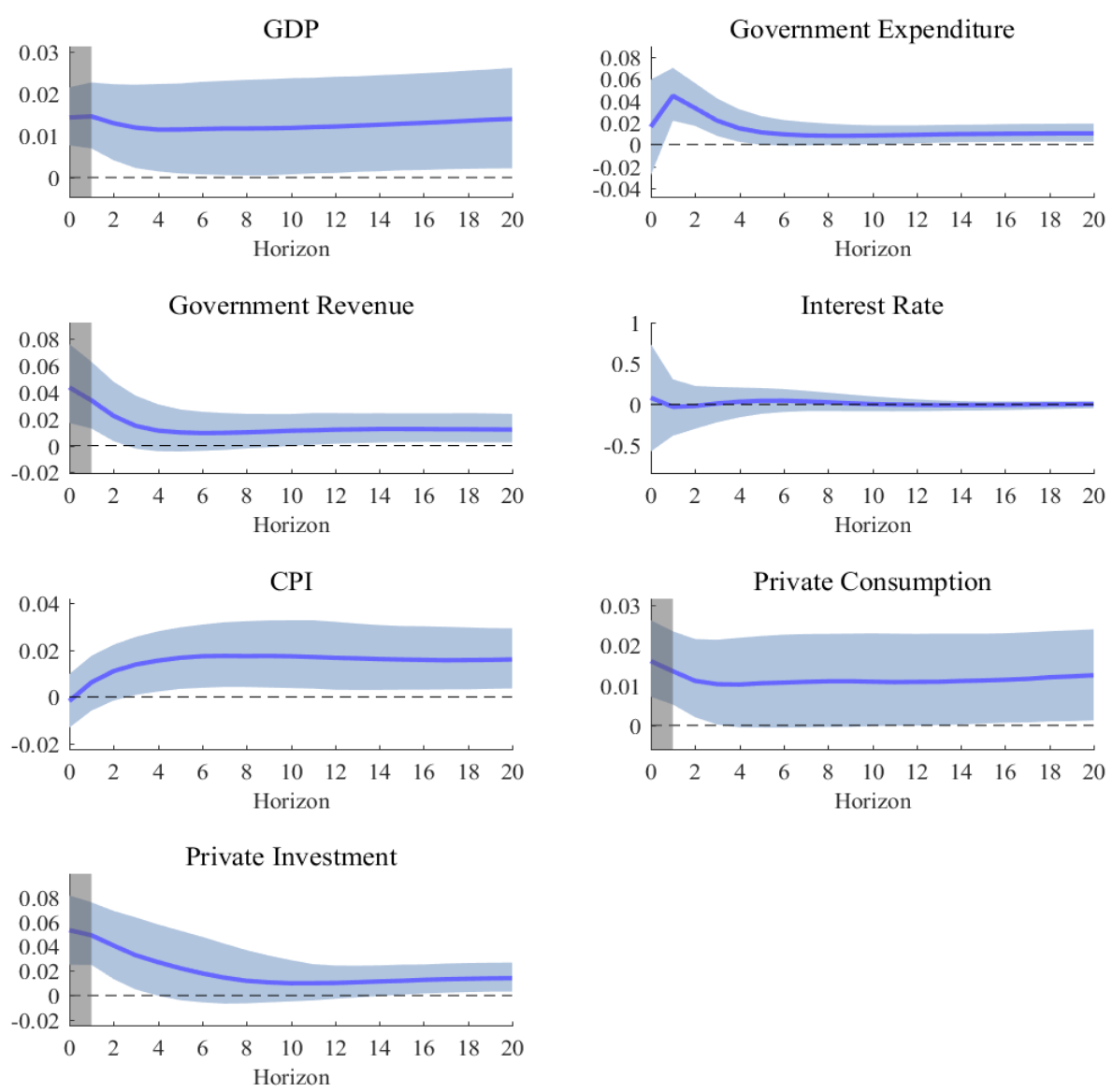

Figure 1. Impulse responses of business cycle shock

Note. The figure shows the 50th (solid line) and the 16th and 84th (shade) quantiles of the impulse responses. The vertical shade represents the imposed restriction on the impulses.

The responses of the monetary policy variable (interest rate) and government expenditure are not restricted in our identification method. It seems that the central bank does not respond to the positive business cycle shock, as the interest rate does not move with this shock. However, government expenditure jumps and remains positive and significant. Mountford and Uhlig (2009) find similar results in the US. This pro-cyclical behavior may be 
due to the fact that the government has more money to spend and feels more comfortable investing in infrastructure projects due to favorable economic conditions.

\subsection{Monetary Policy Shock}

Figure 2 plots the impulse responses of the monetary policy shock, where the interest rate increases and price level decreases for two years by construction. The interest rate returns to zero and becomes insignificant after two years, implying that the impact of the monetary policy shock on the interest rate is not persistent.
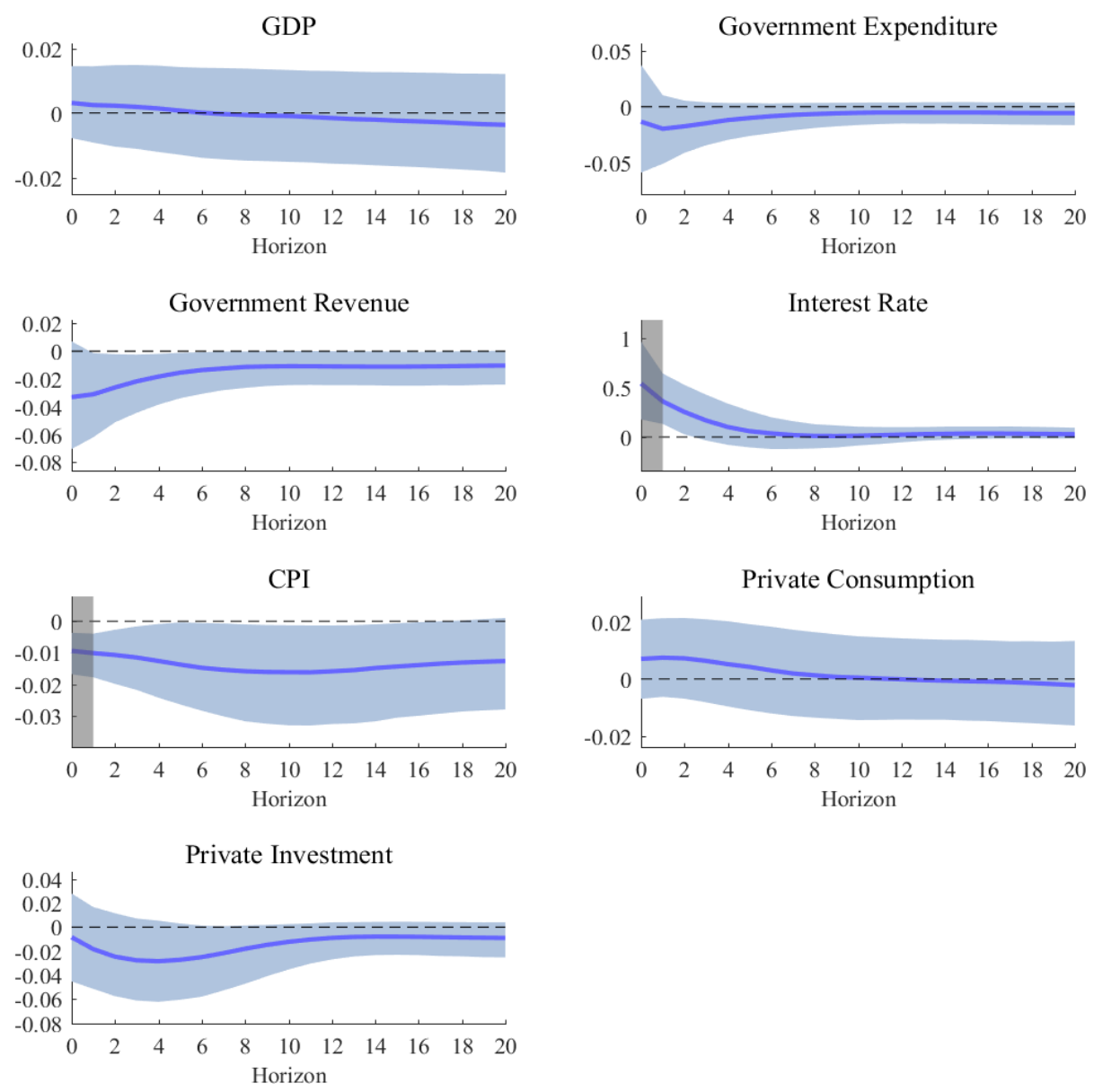

Figure 2. Impulse responses to monetary policy shock

Note. The figure shows the 50th (solid line) and the 16th and 84th (shade) quantiles of the impulse responses. The vertical shade represents the imposed restriction on the impulses.

Although we restrict the price level to respond negatively for only two years, the response is significantly negative beyond four years, indicating that contractionary policy reduces price level. However, the response of output is not significant, which accords with the previous finding for Bangladesh in Alam (2015) and Ahmed and Islam (2004). Both private consumption and investment are not significant, although private investment falls after the shock. Government revenue and expenditure both fall, although only the former is significant. One explanation of this counter-cyclical behavior for taxes is that the government cuts taxes in response to contractionary monetary policy to maintain output levels. In sum, monetary policy shocks do not have any impact on real variables. 


\subsection{Unanticipated Government Expenditure Shock}

The impulse responses of the unanticipated government expenditure are plotted in Figure 3. Government expenditure appears to return to zero quickly after the initial shock. Private consumption increases as predicted by neo-Keynesian theory, although the impact is not significant in the current specification, but significant in the 11VAR specification discussed in the robustness check section.
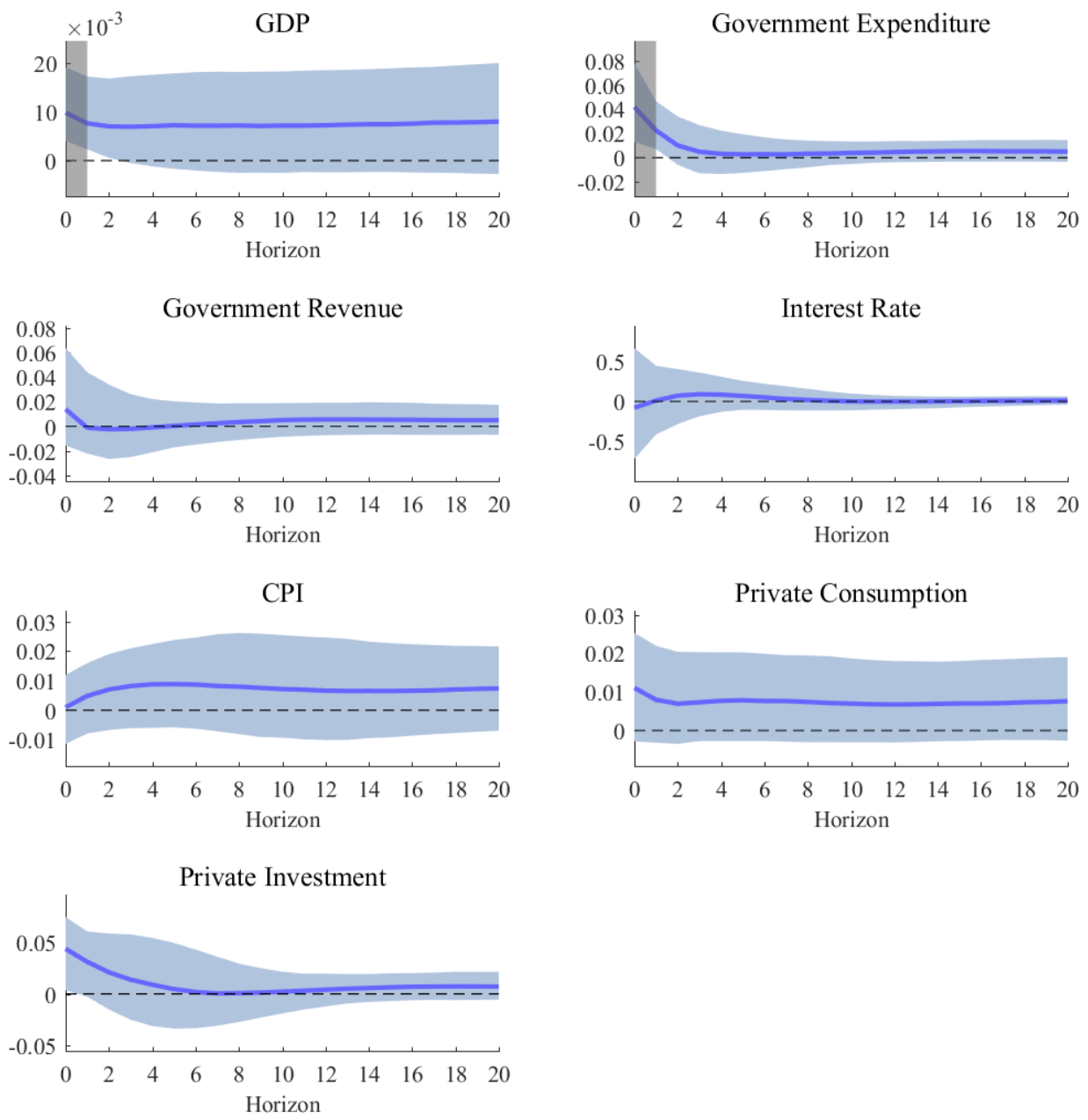

Figure 3. Impulse responses of unanticipated government expenditure shock Note. The figure shows the 50th (solid line) and the 16th and 84th (shade) quantiles of the impulse responses. The vertical shade represents the imposed restriction on the impulses.

The increase in private consumption is also in accord with the findings of other SVAR studies, namely, Blanchard and Perotti (2002) and Mountford and Uhlig (2009). Price level increase, but the response is not significant, although Dungey and Fry (2009) examining New Zealand and Mountford and Uhlig (2009) examining the US find the opposite response. One surprising finding is private investment, which increases at impact and is significant up to two years, even though the interest rate does not respond to the shock. However, Saidjada and Jahan (2018) find that the crowding-out effect slows after the liberalization period (1990), and Majumder (2007) finds a crowding-in effect for Bangladesh, which supports our results. 
As we restrict GDP to be positive in identifying the shock, and the response is minimal, we cannot conclude much about GDP.

\subsection{Anticipated Government Expenditure Shock}

We also identify a year delayed anticipated government expenditure shock, where government expenditure is restricted to zero at horizon zero and then positive in the next horizon (Mountford \& Uhlig, 2009). The impulse responses of this shock are illustrated in Figure 4. Even though government expenditure increases in the next year, all the impulses show immediate response due to the shock, which illustrates perceptive "announcement" effects.
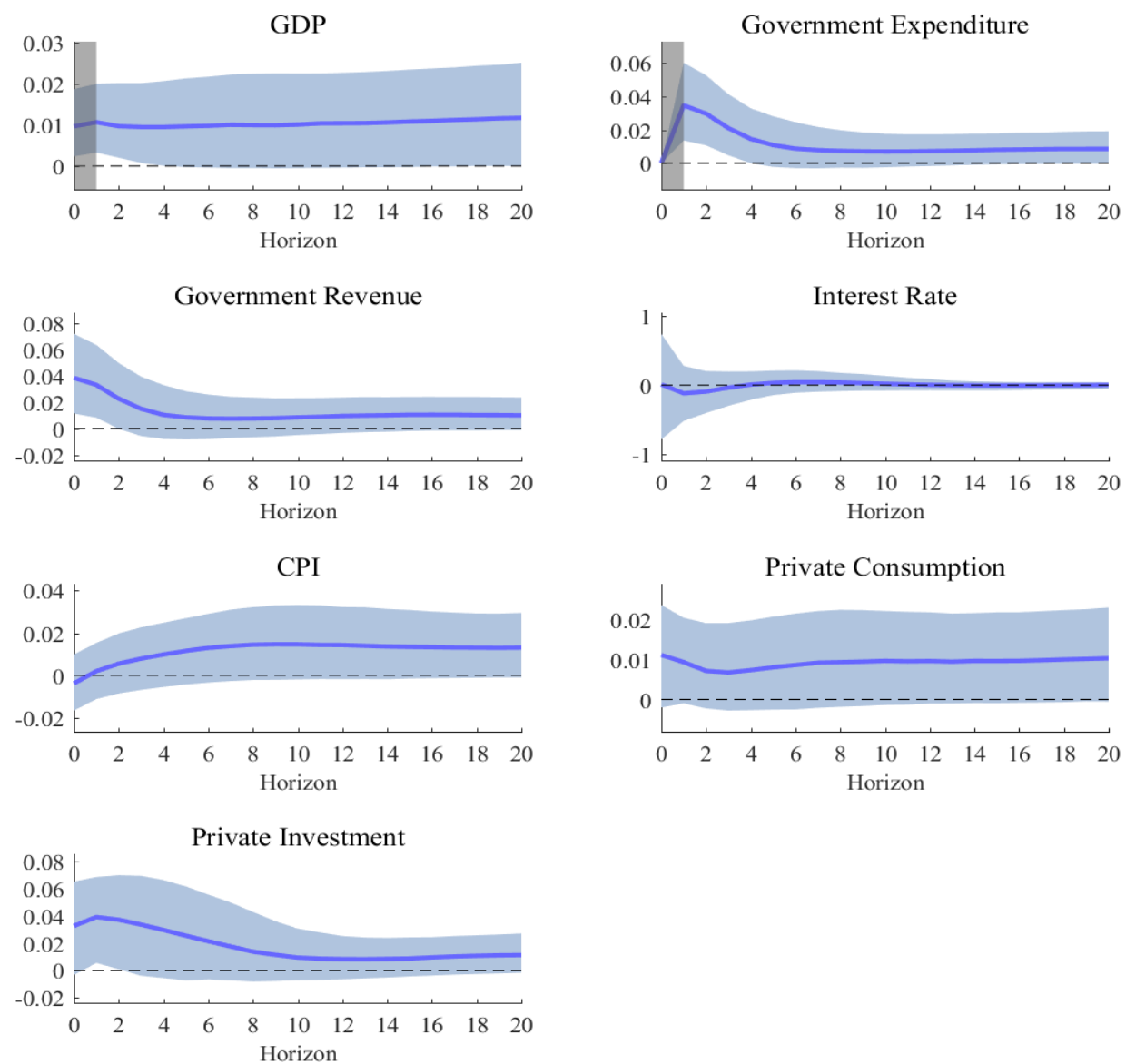

Figure 4. Impulse responses of anticipated government expenditure shock

Note. The figure shows the 50th (solid line) and the 16th and 84th (shade) quantiles of the impulse responses. The vertical shade represents the imposed restriction on the impulses. For the anticipated shock, the fiscal variable is restricted to zero on impact (horizon zero) and positive in horizon one. 
Figure 5 plots the median responses of the anticipated (dashed line) and unanticipated (solid line) government expenditure shocks. Output, private consumption, and private investment increase immediately due to the shock. All the responses have a much stronger effect than the unanticipated shock.
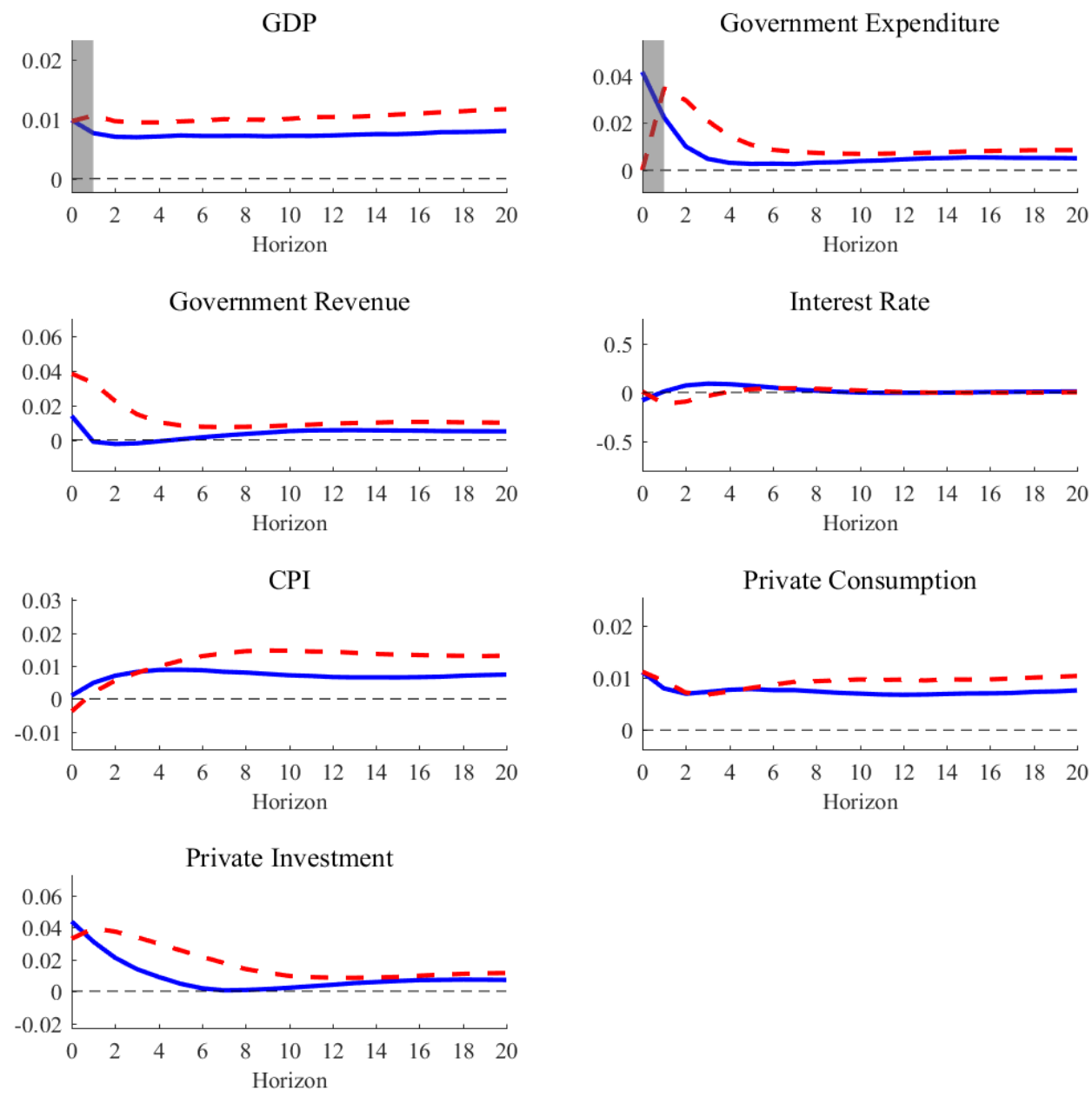

Figure 5. Comparison of median impulse responses of unanticipated and anticipated government expenditure shock

Note. The figure shows the 50th (median) quantile impulse response of the anticipated (dashed line) and unanticipated (solid line) government expenditure shock. The vertical shade represents the imposed restriction on the impulses. For the anticipated shock, the fiscal variable is restricted to zero on impact (horizon zero) and positive in horizon one.

\subsection{Unanticipated Government Revenue Shock}

The impulse responses of the unanticipated government revenue shock are plotted in Figure 6. We do not restrict any impulses except government revenue to identify the shock, meaning that we are agnostic about the responses of all other variables. 

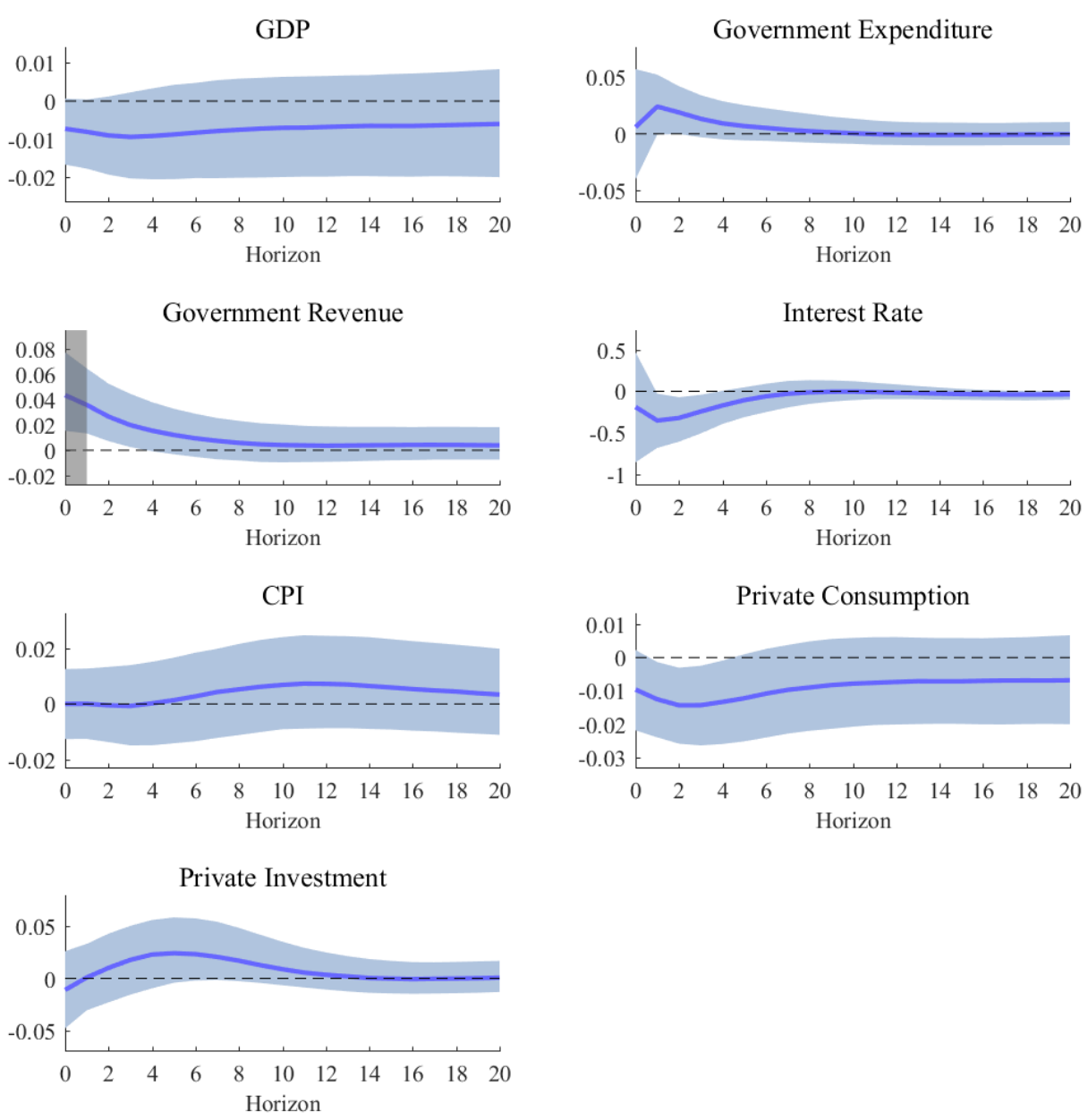

Figure 6. Impulse responses of unanticipated government revenue shock Note. The figure shows the 50th (solid line) and the 16th and 84th (shade) quantiles of the impulse responses. The vertical shade represents the imposed restriction on the impulses.

Output and private consumption fall due to the tax hike, where output is significant up to the second year and private consumption is significant up to the fourth year after the shock. Price level rises after some lag, which is not significant, as in Mountford and Uhlig (2009), although Favero and Giavazzi (2007) and Dungey and Fry (2009) find the opposite. Private consumption turns positive from negative at impact, and is not significant. The behavior of private investment is puzzling. Although the effect is not significant, private investment remains positive up to the $14^{\text {th }}$ horizon after being negative at impact. One explanation could be the fact that the central bank seems to reduce the interest rate to accommodate the tax hike, which, perhaps, leads to an increase in private investment. The decline in the interest rate is consistent with the results in Dungey and Fry (2009) and Favero and Giavazzi (2007). Government expenditure increases and is marginally significant at horizon one because the government has more revenue to spend. 


\subsection{Anticipated Government Revenue Shock}

The impulse responses of a year delayed anticipated government revenue shock are displayed in Figure 7. Due to this shock, output and private consumption do not respond and are also not significant. A comparison of the median responses to the anticipated (dashed line) and unanticipated (solid line) shocks are shown in Figure 8. Compared with unanticipated shocks, anticipated revenue shocks do not have any impact on output and consumption.
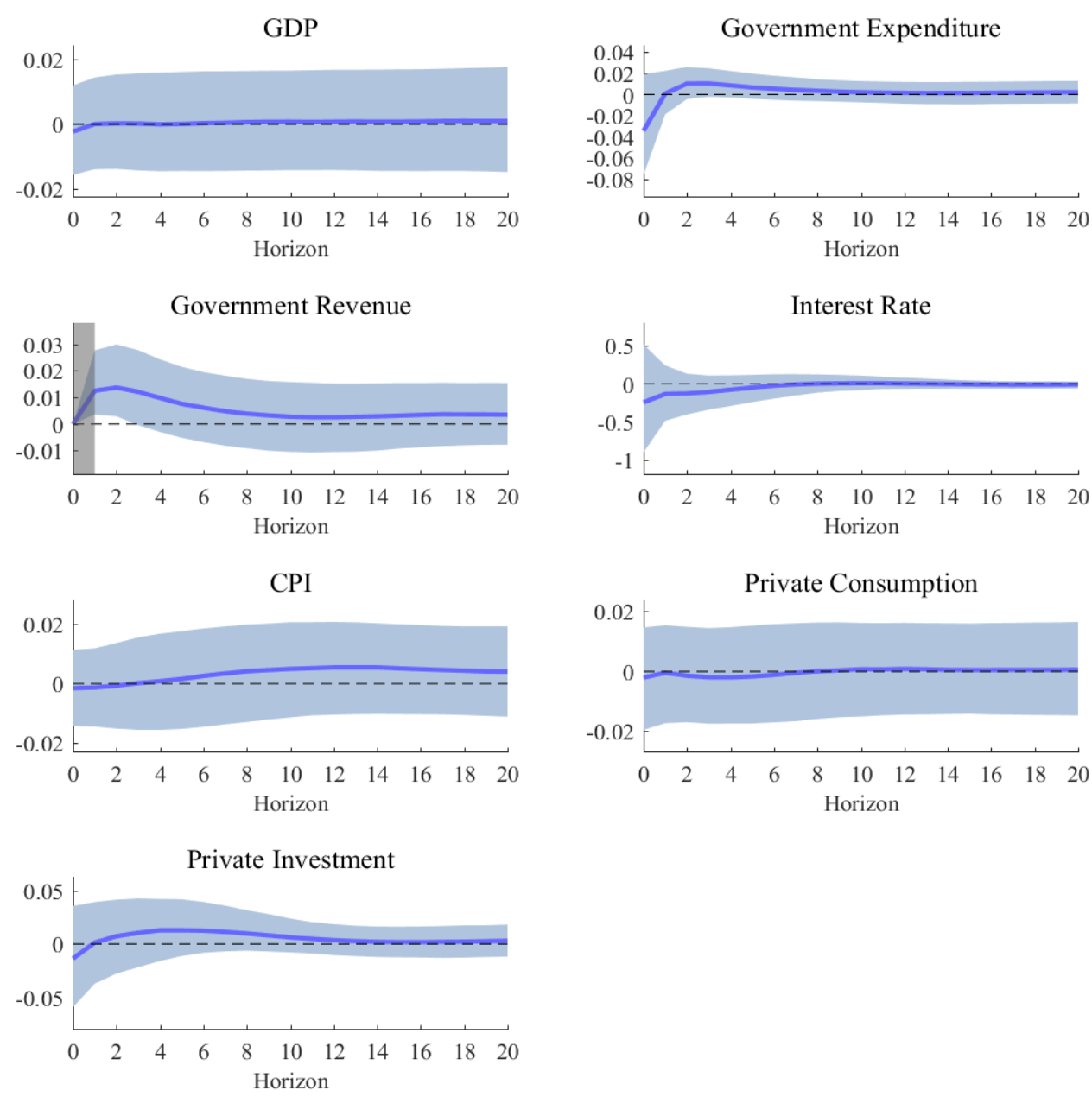

Figure 7. Impulse responses of anticipated government revenue shock

Note. The figure shows the 50th (solid line) and the 16th and 84th (shade) quantiles of the impulse responses. The vertical shade represents the imposed restriction on the impulses. For the anticipated shock, the fiscal variable is restricted to zero on impact (horizon zero), and positive in horizon one.

Therefore, the impact of the anticipated government revenue shock is weaker than that of unanticipated shocks. The economic agents accommodate their behavior in ways so that 
output and consumption remain the same as before.
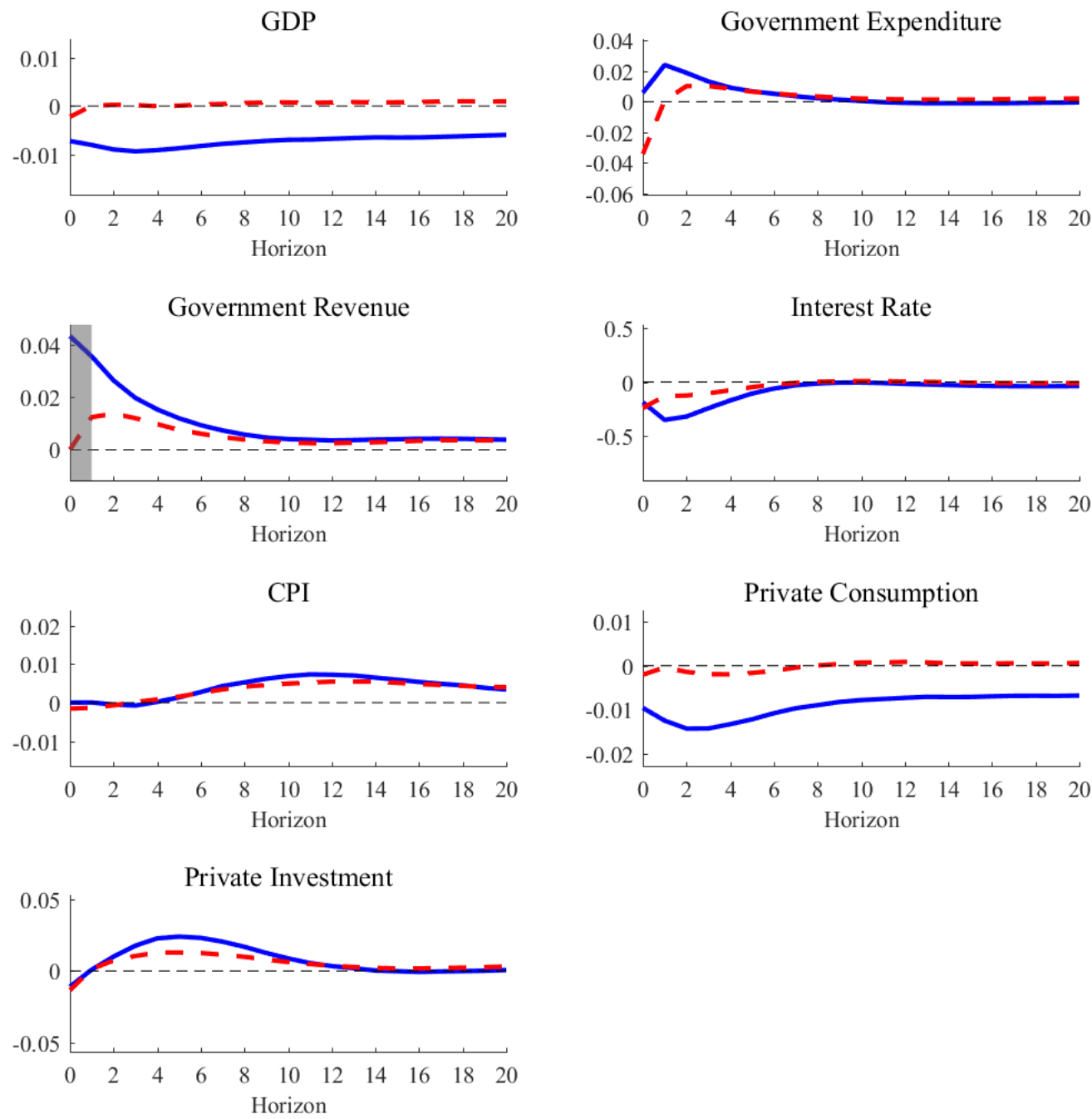

Figure 8. Comparison of median impulse responses of unanticipated and anticipated government revenue shock

Note. The figure shows the 50th (median) quantile impulse response of the anticipated (dashed line) and unanticipated (solid line) government expenditure shock. The vertical shade represents the imposed restriction on the impulses. For the anticipated shock, the fiscal variable is restricted to zero on impact (horizon zero) and positive in horizon one.

\subsection{Fiscal Multipliers}

Our study follows Mountford and Uhlig (2009) to calculate the impact multipliers. The calculated impact multipliers are listed in Table 2. We do not infer the government expenditure multipliers as we restrict GDP in identification. The tax multipliers range from -2.5 to -3.3 in 12 years after the shock, with a maximum of -3.3 in the fourth year. The multipliers are slightly larger in the 5VAR case compared with this base specification (7VAR), with a maximum of -3.7 in the third year (we can provide the results on request). 
Looking at the $68 \%$ credible interval in the bracket, we can infer that tax multipliers are nearly significant up to horizon four.

Table 2

Impact Multipliers

\begin{tabular}{lcccccc}
\hline & 1 year & 2 year & 4 year & 8 year & 12 year & Maximum \\
\hline Gov. expenditure & 2.70 & 2.10 & 1.91 & 1.97 & 1.97 & 2.70 (year 1) \\
& {$[3.5,2.8]$} & {$[2.0,2.5]$} & {$[-0.4,1.9]$} & {$[-2.0,2.7]$} & {$[-2.0,2.7]$} & \\
Tax & -2.57 & -2.85 & -3.32 & -2.78 & -2.46 & -3.32 (year 4) \\
& {$[-16.7,0.1]$} & {$[-17.7,0.1]$} & {$[-20.3,0.5]$} & {$[-20.2,1.1]$} & {$[-19.8,1.3]$} & \\
\hline
\end{tabular}

Note. The $16^{\text {th }}$ and $84^{\text {th }}$ quantiles are shown in brackets. GDP multiplier $=($ GDP response/Initial fiscal shock)/Average share of the fiscal variable to GDP (Mountford \& Uhlig, 2009).

\subsection{Forecast Error Variance Decomposition of GDP}

Figure 9 shows the share of various shocks in the forecast error variance decomposition (FEVD) of GDP from horizons 1 to 20. At horizon 20, about 28\% of the variation in GDP is due to the business cycle and government revenue shocks. Monetary policy contributes about $6 \%$ of the variation, while government expenditure shock barely contributes. The remaining variations are due to residual shocks.

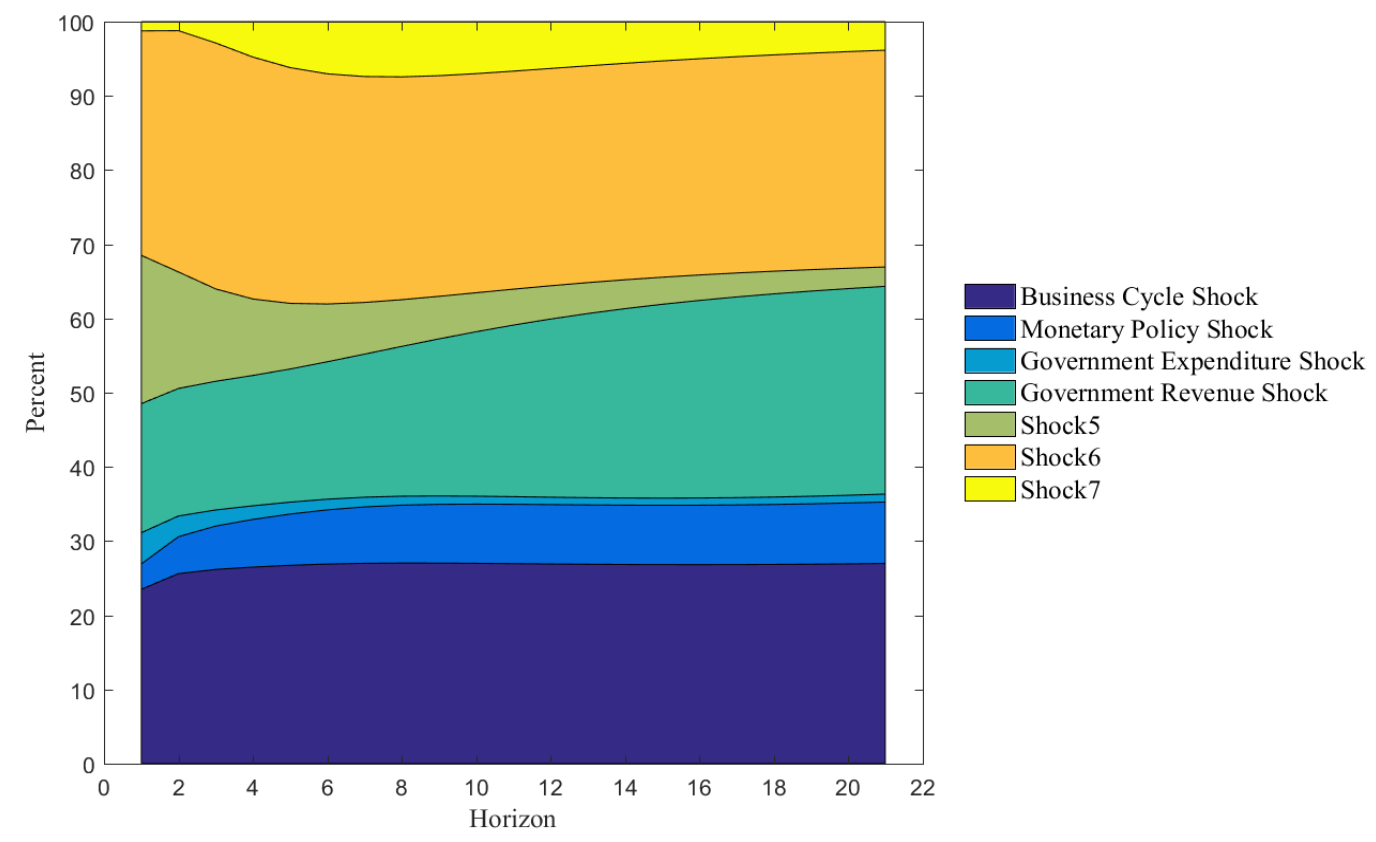

Figure 9. Forecast error variance decomposition (FEDV) of GDP

\subsection{Robustness Check}

We identify the fiscal shocks in the smallest VAR possible, as argued by Fatás and Mihov (2001) and Kabashi (2017). Figures A1 and A2 in the Appendix plot the impulse responses of the government expenditure and revenue shock using only five variables excluding private consumption and investment. The results remain similar to the base 
identification (7VAR). Notably, in the case of government revenue shock, output significantly decreases up to horizon three following a tax hike. The behavior of the interest rate in both cases is also similar. The only difference is that price level fall due to an increase in taxes compared with the 7VAR case.

We also analyze the fiscal shock in the eleven variable VAR system. We include the wage index, as neo-Keynesian and neo-classical models have a prediction about wages (Mountford \& Uhlig, 2009), the external sector component of GDP that includes exports, imports (in per capita real terms), and the exchange rate (BDT per USD) following Dungey and Fry (2009). The impulse responses are shown in Figures A3-A6 in the Appendix.

Figure A3 shows the impulse responses of the business cycle shock. The main conclusions remain valid in the 11VAR specification. GDP, price level, private consumption, and government expenditure increase, and have a persistent impact. The wage index increases and is significant at horizons three to six. Both exports and imports increase and are significant up to horizons one and two, respectively.

The impulse responses of the monetary policy shock are shown in Figure A4. As before, monetary policy does not have any impact on real variables. However, only wages fall due to contractionary monetary policy shocks.

Figure A5 plots the impulse responses of unanticipated government expenditure shocks. Both private consumption and wages rise due to positive government expenditure shock, which accords with neo-Keynesian predictions and is consistent with other SVAR findings (e.g., Blanchard and Perotti, 2002; Fatás and Mihov, 2001; Perotti, 2004; 2007; Mountford and Uhlig, 2009). However, the rise in private consumption is now significant at the end of year two up to year ten after the shock compared with the base specification (7VAR). The increase in wages is not significant. Other conclusions are the same as in the 7VAR specification.

Finally, we plot the impulse responses of the unanticipated government revenue shock in Figure A6. The fall in output due to tax hikes is still significant in the 11VAR specification. Wages increase, although not significant. Other conclusions about private consumption and investment are the same as in the base specification (7VAR). Therefore, the decrease in output due to the tax hike is robust to changes in the number of variables.

\section{Conclusion}

This paper analyzes the effects of fiscal shocks in Bangladesh using annual data from 1974 to 2017, where the shocks are identified using the sign restriction approach of Arias et al. (2018) in the BSVAR framework. To isolate the shocks that arise from the automatic movement of fiscal variables and monetary policy, we identify a generic business cycle and monetary policy shocks following the approach of Mountford and Uhlig (2009). In identifying the government expenditure and revenue shocks, we use minimal sign restriction, and, in particular, we do not impose any restrictions on the sign of the focal variable of interest.

We find that the business cycle shock is persistent and significantly increases price level, GDP, private consumption, and wages, which accords with the demand and supply side explanation of business cycle shock. The monetary policy shock has little impact on real variables, which is consistent with previous studies on the monetary policy of Bangladesh (e.g., Alam, 2005). The government expenditure shock increases private investment, consumption, and wages. Such an increase in private consumption and wage is consistent with the neo-Keynesian prediction and other SVAR results, namely, Blanchard and Perotti (2002) and Mountford and Uhlig (2009), although wage is not significant, and private consumption is not robust to the change in the number of variables in the VAR. The decrease in output due to the tax hike shock is highly robust. Private consumption also falls due to a 
tax increase, although investment does not. Most of the variation in output is due to the business cycle and government revenue shock (around 28\% each), while government expenditure does not contribute.

Our findings have important policy implications for formulating the fiscal policies of Bangladesh. First, as we find that the tax shock significantly alters output, the fiscal authority should use tax policy to guide output to the desired level when necessary. Second, an increase in government expenditure increases private investment instead of reducing it. This implies that the fiscal authority can increase government expenditure without hurting private investment. Finally, the government should use fiscal policy, especially tax policy, rather than monetary policy, to stabilize output. 


\section{References}

Afonso, A., \& Sousa, R. M. (2012). The macroeconomic effects of fiscal policy. Applied Economics, 44(34), 4439-4454.

Ahmed, S., \& Islam, M. E. (2004). The monetary transmission mechanism in Bangladesh: Bank lending and exchange rate channels. The Bangladesh Development Studies, 30(3), 31-87.

Alam, M. R. (2015). Effectiveness of monetary policy in Bangladesh. The Journal of Developing Areas, 49(2), 363-372.

Arias, J. E., Rubio-Ramírez, J. F., \& Waggoner, D. F. (2014). Inference based on SVAR identified with sign and zero restrictions: theory and applications (Dynare Working PapersNo. 30), CEPREMAP.Retrieved from https://www.dynare.org/wp-repo/dynarewp030.pdf

Arias, J. E., Rubio-Ramírez, J. F., \& Waggoner, D. F. (2018). Inference based on structural vector autoregressions identified with sign and zero restrictions: Theory and applications. Econometrica, 86(2), 685-720.

Baumeister, C., \& Hamilton, J. (2015). Sign restrictions, structural vector autoregressions, and useful prior information. Econometrica, 83(5), 1963-1999.

Baxter, M., \& King, R. G. (1993). Fiscal policy in general equilibrium. American Economic Review, 83(3), 315-334.

Bernanke, B. S. (1986). Alternative explanations of the money-income correlation (CarnegieRochester Confer. Series on Public PolicyVol. 25). Retrieved from https://doi.org/10.1016/0167-2231(86)90037-0

Blanchard, O., \& Perotti, R. (2002). An empirical characterization of the dynamic effects of changes in government spending and taxes on output. The Quarterly Journal of Economics, 117(4), 1329-1368.

Blanchard, O., \& Quah, D. (1989). The dynamic effects of aggregate demand and supply disturbances. American Economic Review, 79(4), 655-673.

Breitenlechner, M., Geiger, M., \& Sindermann, F. (2019). ZeroSignVAR: A Zero and Sign Restriction Algorithm Implemented in MATLAB.Unpublished manuscript, University of Innsbruck. Retrieved from https://eeecon.uibk.ac.at/ breitenlechner/data/Vignette.pdf

Canova, F., \& Pappa, E. (2007). Price differentials in monetary unions: the role of fiscal shocks. Economic Journal, 117(520), 713-737.

Dieppe, A., Legrand, R., \& Roye, B. Van. (2016). The BEAR toolbox (ECB Working PaperNo. 1934).Retrieved from https://dx.doi.org/10.2866/292952

Ducanes, G., Cagas, M. A., Qin, D., Quising, P. F., \& Razzaque, M. A. (2006). Macroeconomic effects of fiscal policies: empirical evidence from Bangladesh, China, Indonesia and the Philippines (ERD Working Paper Series No. 85), ADB. Retrieved from https://www.adb.org/sites/default/files/publication/28204/wp085.pdf

Dungey, M., \& Fry, R. (2009). The identification of fiscal and monetary policy in a structural VAR. Economic Modelling, 26(6), 1147-1160.

Fatás, A., \& Mihov, I. (2001). The effects of fiscal policy on consumption and employment.Fiscal policy (Vol. 2760). Citeseer. 
Faust, J. (1998). The robustness of identified VAR conclusions about money (Carnegie Rochester Conference Series on Public Policy No. 49), 207-244.

Favero, C.,\& Giavazzi, F. (2007). Debt and the effects of fiscal policy (NBER Working Paper No. 12822), Retrieved from https://doi.org/10.2139/ssrn.1002383

Galí, J. (1992). How well does the IS-LM model fit postwar U. S. data? The Quarterly Journal of Economics, 107(2), 709-738.

Kabashi, R. (2017). Macroeconomic effects of fiscal policy in the European Union, with particular reference to transition countries. Public Sector Economics, 41(1), 39-69.

Majumder, A. (2007). Does public borrowing crowd-out private investment? The Bangladesh evidence (Bangladesh Bank Working Paper Series No. WP708, Policy Analysis Unit).

Mountford, A., \& Uhlig, H. (2009). What are the effects of fiscal policy shocks? Journal of Applied Econometrics, 24(6), 960-992.

Nahar, B., \& Siriwardana, M. (2013). Trade opening, fiscal reforms, poverty, and inequality: a cge analysis for Bangladesh. The Developing Economies, 51(2), 145-185.

Perotti, R. (2004). Estimating the effects of fiscal policy in OECD countries (IGIER Working Paper No. 276). Retrieved from http://dx.doi.org/10.2139/ssrn.637189

Perotti, R. (2007). In search of the transmission mechanism of fiscal policy (NBER Working Papers No. 13143). Retrieved from National Bureau of Economic Research, Inc, http://www.nber.org/papers/w13143.pdf

Ramey, V. A. (2011). Identifying government spending shocks: It's all in the timing. The Quarterly Journal of Economics, 126(1), 1-50.

Ramey, V. A., \& Shapiro, M. D. (1998). Costly capital reallocation and the effects of government spending (Carnegie-Rochester Conference Series on Public Policy,48), 145194.

Romer, C. D., \& Romer, D. H. (2010). The macroeconomic effects of tax changes: estimates based on a new measure of fiscal shocks. American Economic Review, 100(3), 763-801.

Saidjada, K. M., \& Jahan, S. I. (2018). Public and private investment nexus in Bangladesh: crowding-in or out? Journal of Developing Areas, 52(4), 115-127.

Sims, C. (1986). Are forecasting models usable for policy analysis? Quarterly Review, Winter, 2-16.

Uhlig, H. (1994). What macroeconomists should know about unit roots: a bayesian perspective. Econometric Theory, 10(3-4), 645-671.

Uhlig, H. (2005). What are the effects of monetary policy on output? Results from an agnostic identification procedure. Journal of Monetary Economics, 52(2), 381-419. 


\section{Appendix}
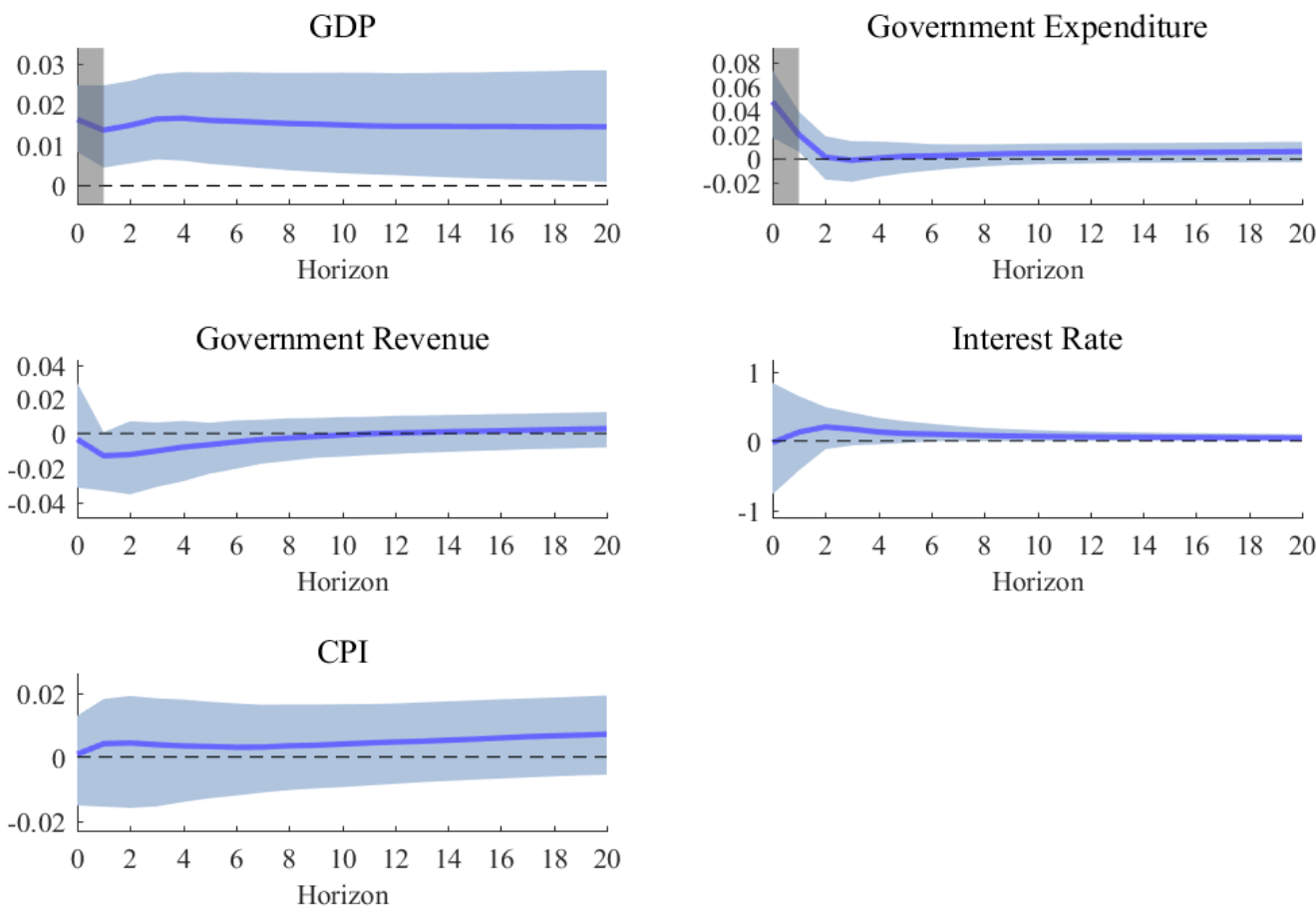

Figure A1. Impulse responses of unanticipated government expenditure shock under 5VAR
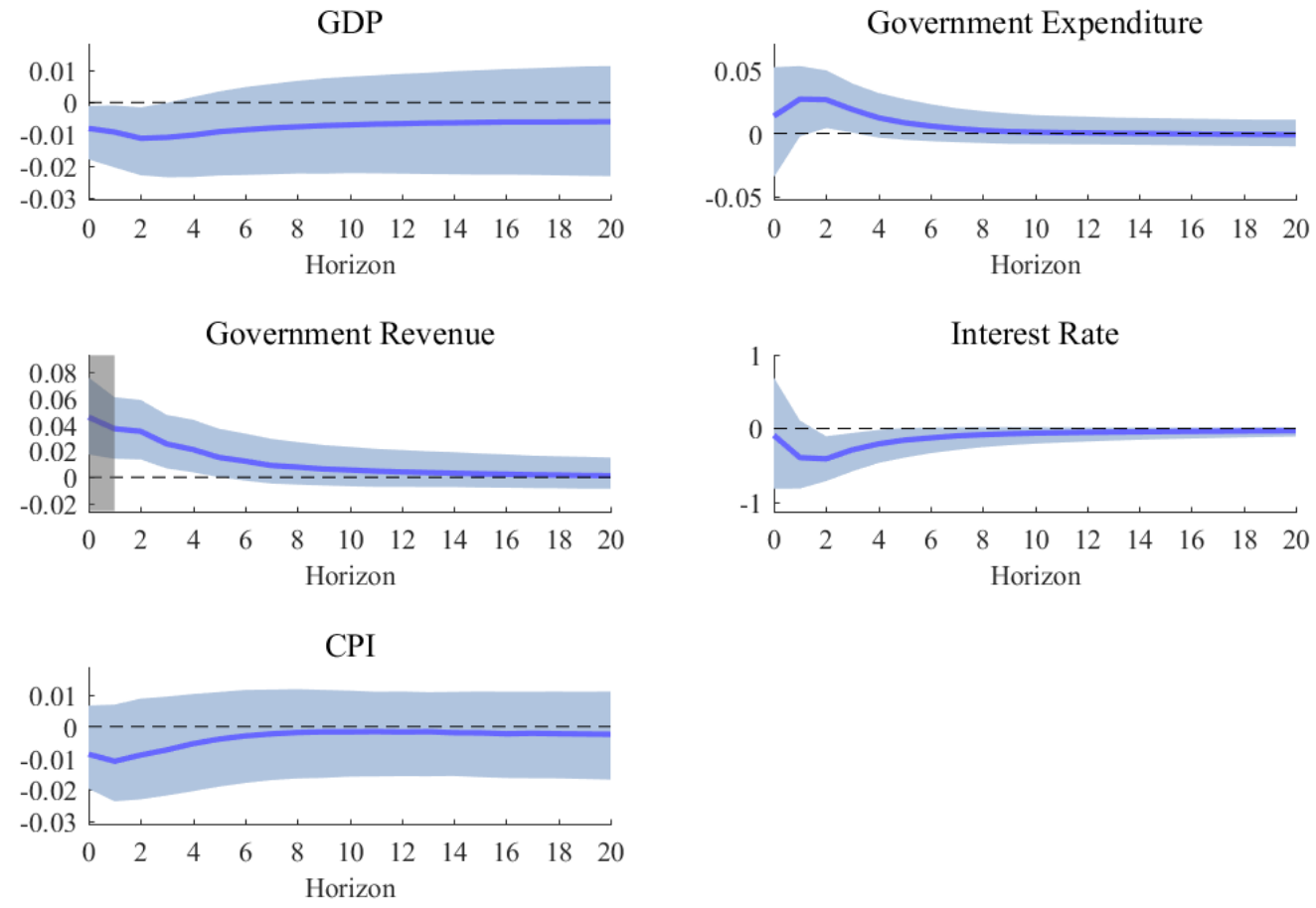

Figure A2. Impulse responses of unanticipated government revenue shock under 5VAR 

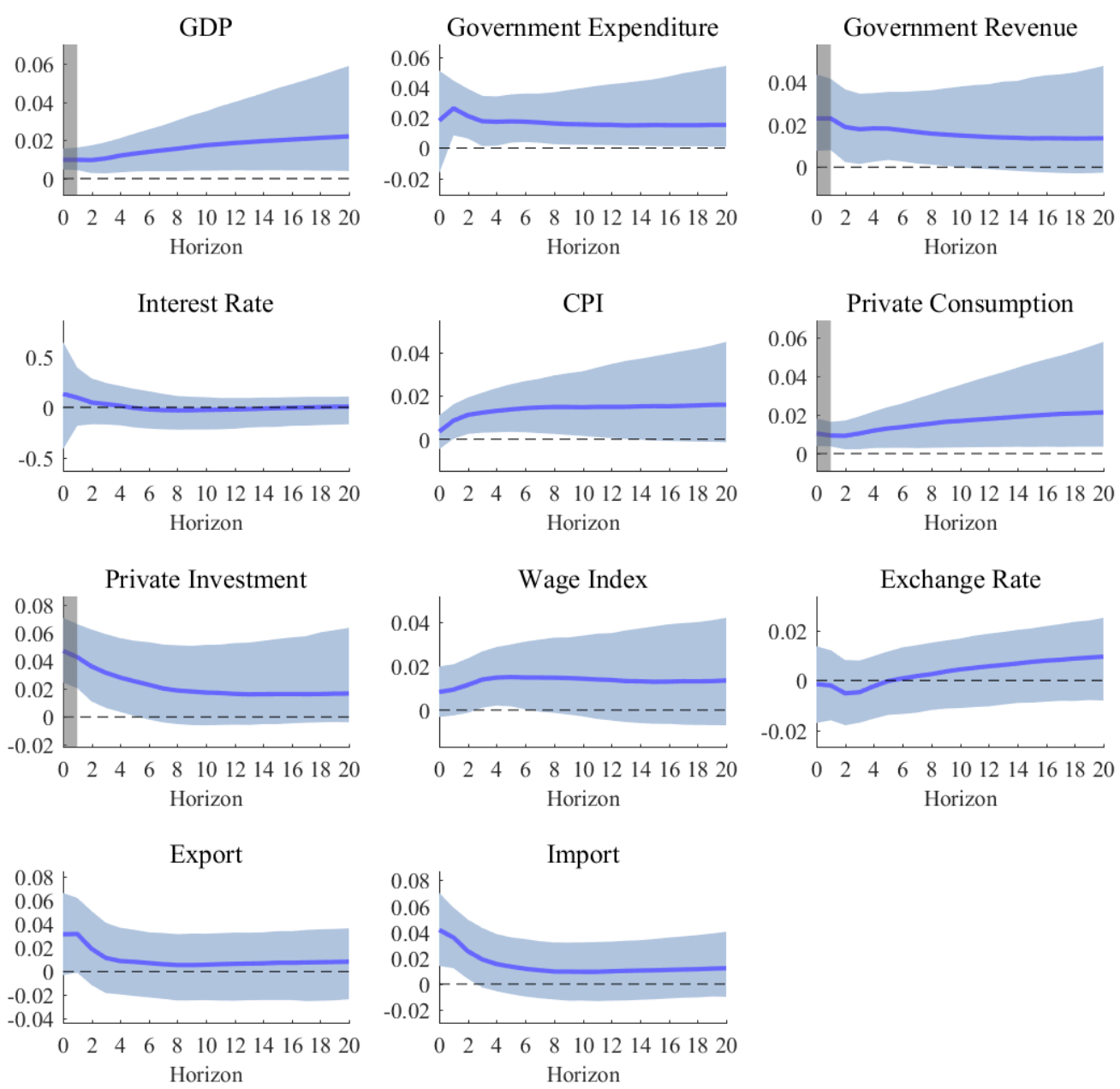

Figure A3. Impulse responses of business cycle shock

Note. The figure shows the 50th (solid line) and the 16th and 84th (shade) quantiles of the impulse responses. The vertical shade represents the imposed restriction on the impulses. 

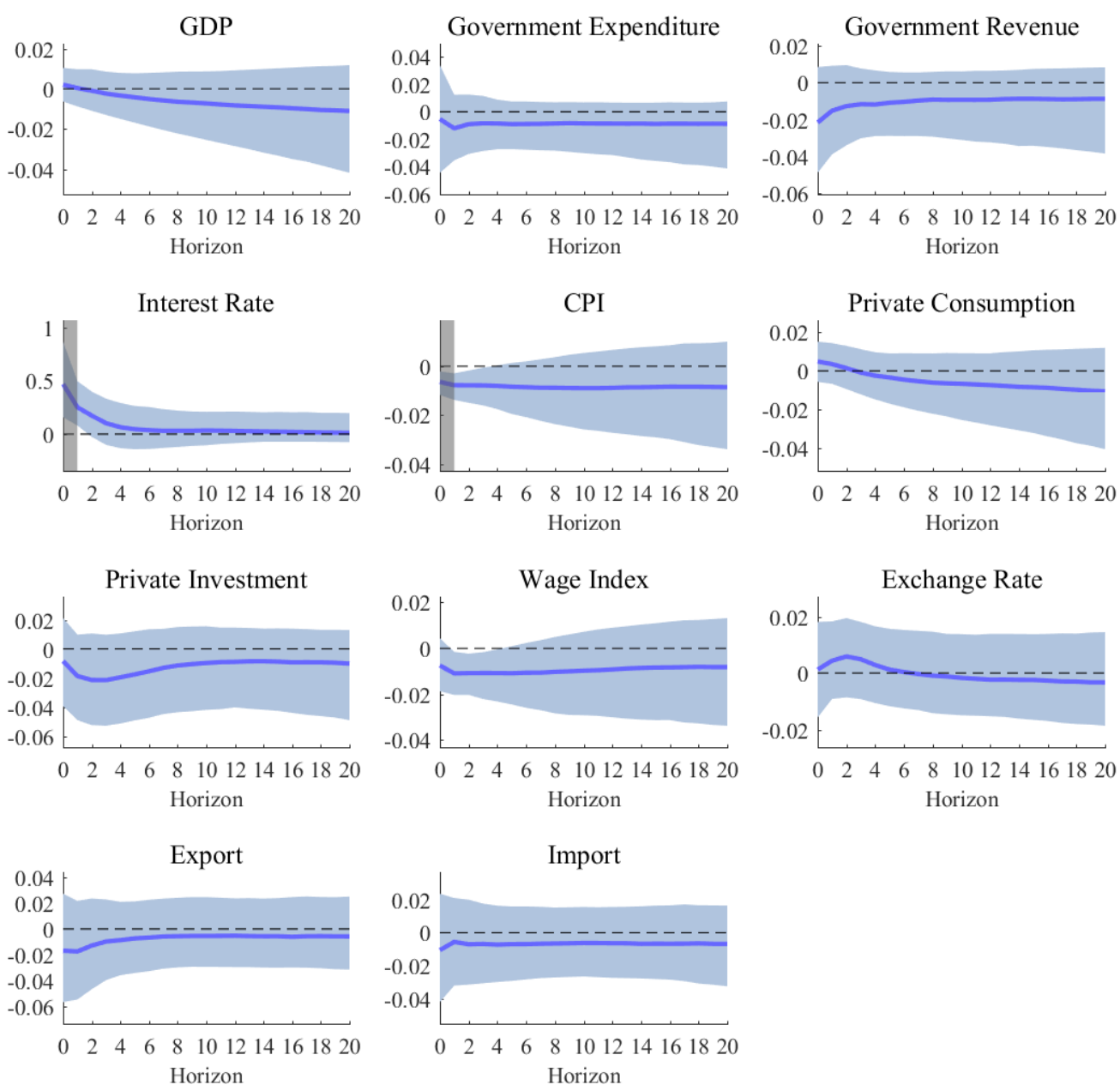

Figure A4. Impulse responses of monetary policy shock

Note. The figure shows the 50th (solid line) and the 16th and 84th (shade) quantiles of the impulse responses. The vertical shade represents the imposed restriction on the impulses. 

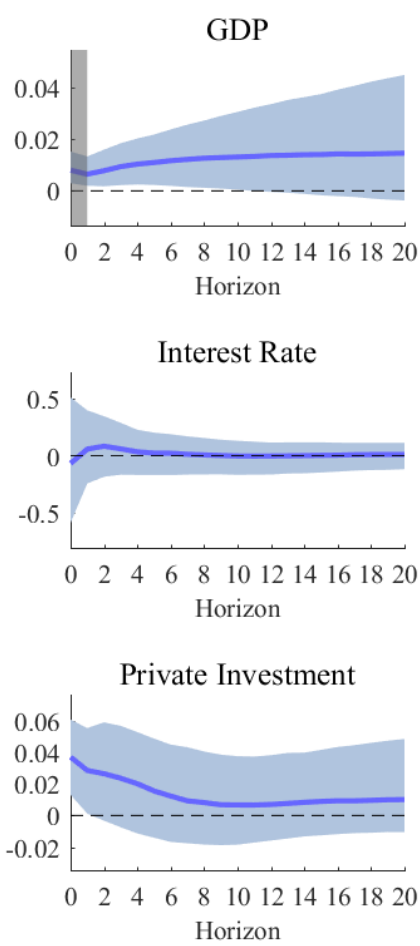

Export

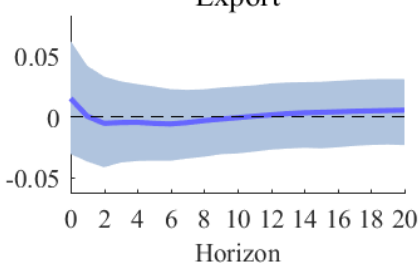

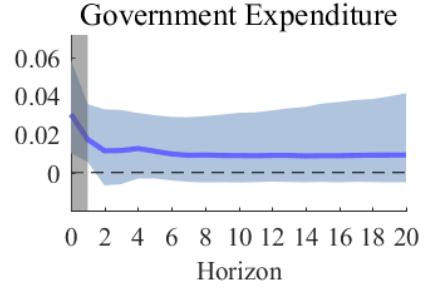

CPI

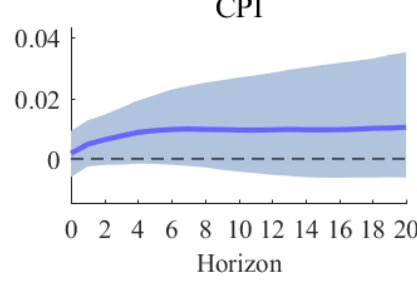

Wage Index

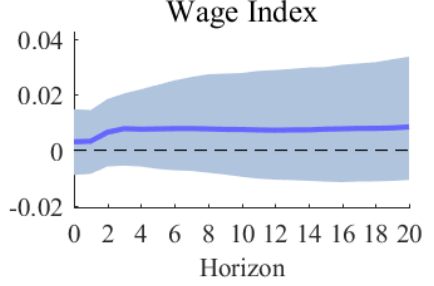

Import

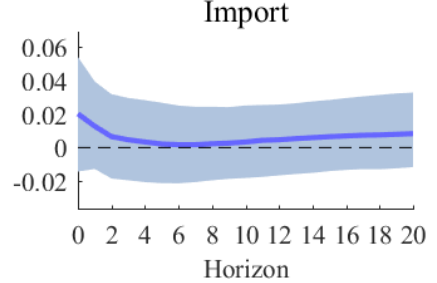

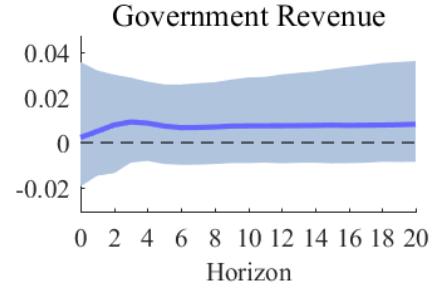

Private Consumption

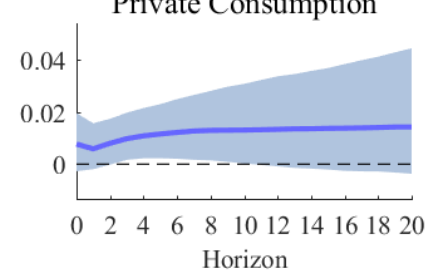

Exchange Rate

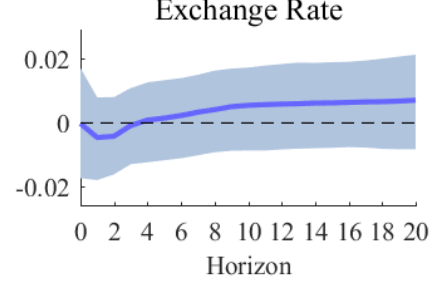

Figure A5. Impulse responses of unanticipated government expenditure shock Note. The figure shows the 50th (solid line) and the 16th and 84th (shade) quantiles of the impulse responses. The vertical shade represents the imposed restriction on the impulses. 

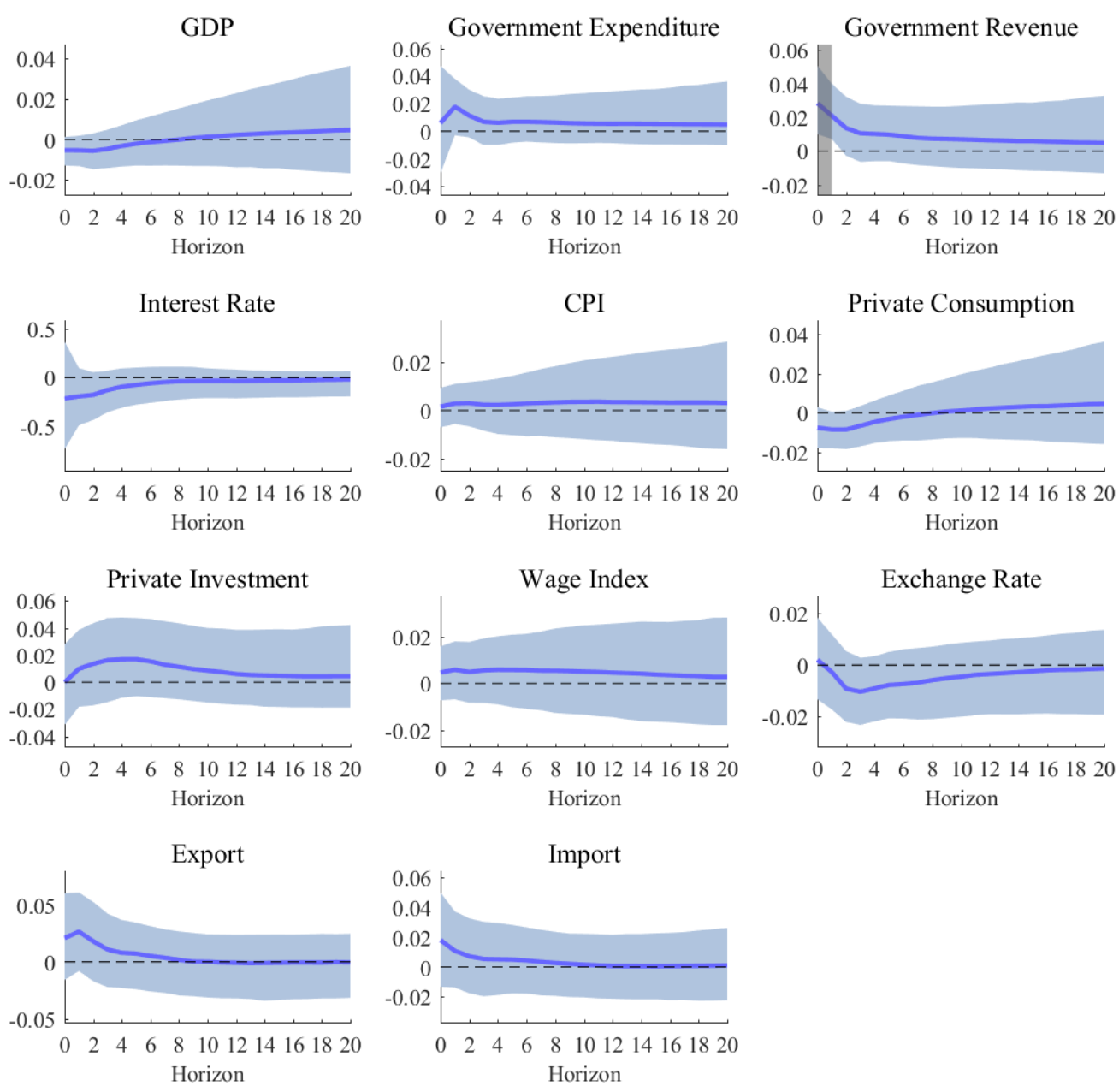

Figure A6. Impulse responses of unanticipated government revenue shock

Note. The figure shows the 50th (solid line) and the 16th and 84th (shade) quantiles of the impulse responses. The vertical shade represents the imposed restriction on the impulses. 